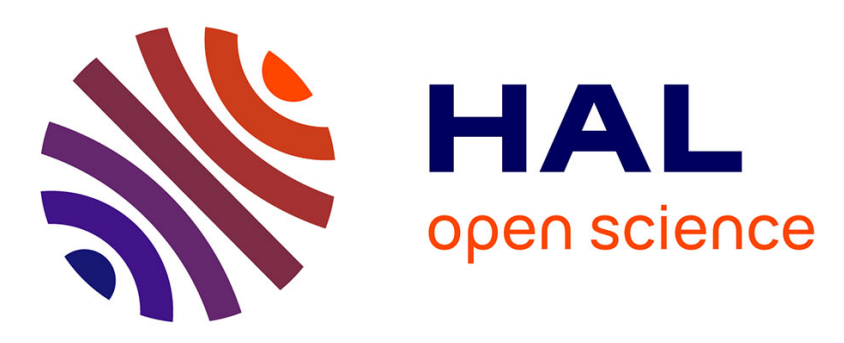

\title{
PBPK model of methotrexate in cerebrospinal fluid ventricles using a combined microdialysis and MRI acquisition
}

Nolwenn Brandhonneur, Fanny Noury, Arnaud Bruyère, Hervé Saint-Jalmes, Pascal Le Corre

\section{To cite this version:}

Nolwenn Brandhonneur, Fanny Noury, Arnaud Bruyère, Hervé Saint-Jalmes, Pascal Le Corre. PBPK model of methotrexate in cerebrospinal fluid ventricles using a combined microdialysis and MRI acquisition. European Journal of Pharmaceutics and Biopharmaceutics, 2016, 104, pp.117-130. 10.1016/j.ejpb.2016.04.012 . hal-01335562

\section{HAL Id: hal-01335562 https://hal.science/hal-01335562}

Submitted on 11 Dec 2016

HAL is a multi-disciplinary open access archive for the deposit and dissemination of scientific research documents, whether they are published or not. The documents may come from teaching and research institutions in France or abroad, or from public or private research centers.
L'archive ouverte pluridisciplinaire HAL, est destinée au dépôt et à la diffusion de documents scientifiques de niveau recherche, publiés ou non, émanant des établissements d'enseignement et de recherche français ou étrangers, des laboratoires publics ou privés. 


\section{PBPK model of methotrexate in cerebrospinal fluid ventricles using a combined microdialysis and MRI acquisition}

Nolwenn Brandhonneur ${ }^{a, b}$, Fanny Noury ${ }^{a, c,{ }^{*},}$ Arnaud Bruyère ${ }^{a, b,{ }^{*},}$

Hervé Saint-Jalmes ${ }^{\mathrm{a}, \mathrm{c}, \mathrm{d}}$ and Pascal Le Corre ${ }^{\mathrm{a}, \mathrm{b}, \mathrm{e}}$

a Université de Rennes 1, Rennes, France

${ }^{b}$ Laboratoire de Pharmacie Galénique, Biopharmacie et Pharmacie Clinique, IRSET

U1085, Rennes, France

${ }^{\text {c} L T S I, ~ I N S E R M, ~ U M R ~ 1099, ~ R e n n e s, ~ F r a n c e ~}$

${ }^{d}$ CRLCC, Centre Eugène Marquis, Rennes, France

e Pôle Pharmacie, CHU de Rennes, France

* These authors contributed equally to this paper

Pr. Pascal Le Corre, corresponding author

Laboratoire de Pharmacie Galénique, Biopharmacie et Pharmacie Clinique,

Faculté des Sciences Pharmaceutiques et Biologiques,

Université de Rennes 1 ,

35043 Rennes Cedex, France.

Phone +332232348

Fax $\quad+33223234846$

Email pascal.le-corre@univ-rennes1.fr

Running head : methotrexate cerebrospinal pharmacokinetics 


\section{ABSTRACT}

To evaluate the distribution of methotrexate (MTX) in cerebrospinal fluid (CSF) lateral ventricles and in cisterna magna after $3^{\text {rd }}$ intraventricular CSF administration in a rabbit model.

MTX or Gadolinium chelate (Gd-DOTA) was administered in the $3^{\text {rd }}$ ventricle with a local microdialysis to study the pharmacokinetics at the site of administration and with a simultaneous magnetic resonance imaging (MRI) acquisition in the $3^{\text {rd }}$ ventricle, the lateral ventricles and in the cisterna magna. A specific CSF Physiologically based Pharmacokinetic (PBPK) model was then extrapolated for MTX from Gd-DOTA data.

The relative contribution of elimination and distribution processes to the overall disposition of MTX and Gd-DOTA in the $3^{\text {rd }}$ ventricle were similar (i.e., around $60 \%$ for CLE and $40 \%$ for CLI) suggesting that Gd-DOTA was a suitable surrogate marker for MTX disposition in ventricular CSF. The PBPK predictions for MTX both in CSF of the $3^{\text {rd }}$ ventricle and in plasma were in accordance with the in vivo results.

The present study showed that the combination of local CSF microdialysis with MRI acquisition of the brain ventricles and a PBPK model could be a useful methodology to estimate the drug diffusion within CSF ventricles after direct brain CSF administration. Such a methodology would be of interest to clinicians for a rationale determination and optimization of drug dosing parameters in the treatment of leptomeningeal metastases. 
Key words: methotrexate, CSF ventricle administration, Gd-DOTA, MRI, PBPK modeling.

\section{Abbreviations:}

CSF: cerebrospinal fluid

MTX: methotrexate

PET: positron emission tomography

PBPK: Physiologically based Pharmacokinetics

MRI: Magnetic resonance Imaging

IM: Intramuscular administration

IV: Intravenous administration

Gd-DOTA: Gadolinium chelate

AUC : area under curve

CLE : elimination clearance

CLI : intercompartmental distribution clearance

RVT : rich-vascularized tissue

PVT : poor-vascularized tissue

$\mathrm{RL}$ : relative loss of microdialysis internal standard

$\mathrm{RR}$ : relative recovery of analyte

PBPK : Physiologically Based Pharmacokinetic Modeling 


\section{INTRODUCTION}

The meninges are a unique site of recurrence of malignancies as a result of a rather limited penetration of systemically administered anticancer drugs through the bloodbrain barrier.

In association with systemic chemotherapy or radiotherapy, direct CSF administration of anticancer drugs, either via intrathecal or intraventricular route, has proved to be an effective strategy for the prevention and the primary treatment of leptomeningeal leukemia's and lymphomas while leptomeningeal metastases from solid tumors usually respond less to intrathecal chemotherapy [1-3].

Currently, only MTX and cytarabine are routinely used intrathecally, and most of the times in association with hydrocortisone. These cell-cycle specific drugs, acting during the $\mathrm{S}$ phase of the cell-cycle, are most effective if drug concentrations are maintained for a long period of time. This requires either repeated intrathecal administration via lumbar punctures or a neurosurgical placement of an indwelling ventricular access device (i.e., Ommaya reservoir).

Continuous administration of $10 \mathrm{mg}$ MTX for five consecutive days in a lateral ventricle via a subcutaneous port has led to concentrations exceeding the therapeutic levels of $10^{-6} \mathrm{M}$ with reduced complications [4].

Alternatively, a slow-release formulation of cytarabine as multivesicular particles leads to a prolonged exposure (elimination half-life around $50-60 \mathrm{hrs}$ ), approximately fortytimes longer than standard cytarabine [5]. Although such a formulation has a pharmacokinetic advantage over the standard formulation as a result of a reduced frequency and total number of administrations, severe neurologic events have been described [6]. 
Besides these two routinely used drugs, in order to improve the management of neoplastic meningitis, several anticancer agents have been studied in animal models: topotecan [7] and karenitecin, a lipophilic camptothecin [8], gemcitabine in nonhuman primates [9-10] and pemetrexed in rats [11].

Phase I clinical trials have been performed especially in children showing that topotecan [12] and busulfan [13] are rather well tolerated and are promising newer agents for treatment of leptomeningeal disease. However, gemcitabine that has preclinical and clinical activities against a wide variety of solid tumors as well as leukemia's and lymphomas, has been shown to have a potential for severe neurotoxicity in adults [14]. In central nervous system, dissemination of non-Hodgkin's lymphoma is a significant cause of morbidity and death. A phase I study of the antiCD20 monoclonal antibody rituximab given as monotherapy via intraventricular route (10 to $50 \mathrm{mg}$ ) showed encouraging results and suggested the association with methotrexate [15]. However, in a clinical series of patients, association of rituximab and liposomal aracytine in recurrent lymphomatous meningitis has led to a modest palliative activity [16].

As new drugs have not yet improved significantly the outcome of neoplastic meningitis, optimization of the route of administration has been studied. Recently, preclinical studies in a piglet model have showed that continuous administration directly in the $4^{\text {th }}$ ventricle would have a potential pharmacokinetic advantage over lumbar or lateral ventricular administration [17-18]. Etoposide (2.5 mg) and MTX (2 mg) administration on five consecutive days did not lead clinical or radiographic evidence of damage with much higher concentrations in the $4^{\text {th }}$ ventricle than in the lumbar cistern. 
It is clear that concurrent research on new drug candidates for intrathecal therapy and improvement on intrathecal administration are needed to optimize the management of neoplastic meningitis. However, there is a critical factor that has not been yet clearly addressed and that deserves much attention. This factor is the 3-Dimensional (3D) biodistribution of the drugs within the cerebral CSF in order to make sure that therapeutic unbound drug concentrations are obtained at cancer cells. Indeed, drug efficacy of this local chemotherapy may be impeded by an uneven distribution. Hence, the knowledge of drug concentration in different parts of these spaces is of paramount interest for a rationale determination and the optimization of the parameters of drug dosing (dose, concentration, volume and speed of injection, additional drugs to modify MTX clearance such as transporter inhibitors).

Several authors have studied with the pharmacokinetics of anticancer agents injected intrathecally either after intraventricular (lateral ventricle or $4^{\text {th }}$ ventricle) or lumbar administration with a majority of studies performed with MTX either in humans [19-20] or in a nonhuman primates model allowing the description of the neural tissue distribution [21-23].

If the CSF distribution of drugs along the neuraxis is quite well documented, this is not the case for the distribution within the brain ventricles. Such point is of crucial significance since anticancer drugs administrated via a ventricle have to diffuse within cerebral CSF to reach cancer cells.

To study the 3D drug distribution, positron emission tomography (PET) after intraventricular administration would be an interesting method. PET studies with the administration of a carbon-11-labelled (11C) or fluorine-18-labelled (18F) drug candidate allow describing the drug concentration-time profile in body spaces targeted 
for the treatment. $18 \mathrm{~F}$ is the most attractive $\mathrm{PET}$ radioisotope allowing for imaging durations of up to ten hours. However, a significant drawback stems from the fact that drug molecules contain fluorine in their native structure are rare. Hence, despite its rather short half-life (around $20 \mathrm{~min}$ ), the majority of PET studies are performed with 11C drug molecules. Furthermore, particular challenges in the synthesis of PET radiotracers include time constraints due to the short radioactive half-lives of the radioisotopes, the need for automatization of procedures to protect from radiation exposure and the necessity to produce a radiotracer which meets the quality criteria of a drug for intrathecal injection into humans. For those reasons PET studies may not be the ideal approach.

Magnetic resonance imaging $(\mathrm{MRI})$ is a noninvasive technique providing highresolution anatomical information with excellent soft tissues contrast, and the ability to reconstruct a 3D representation of a volume of interest. Gadolinium-enhanced MRI further increases the contrast on $T_{1}$-weighted $M R$ images of anatomical regions of interest. From these images, it is possible to calculate the relative concentration of gadolinium in the tissue of interest as a function of time. Microdialysis is particularly relevant to study the disposition of drugs because it allows sampling in biological spaces without altering the local hydrodynamics that could interfere with the disposition of the drug. This is particularly relevant for CSF that has a low flow instead of blood. This technique measures unbound concentrations, and has found significant applications in pharmacokinetics in animals but also in humans (24-26).

The aim of the study was to evaluate the distribution of methotrexate (MTX) in cerebrospinal fluid (CSF) lateral ventricles and in cisterna magna after $3^{\text {rd }}$ intraventricular CSF administration in a rabbit model. For that purpose we used a 
combination of CSF intraventricular microdialysis with MRI after administration of a contrast agent in a ventricle which would allow a quantitative evaluation of the 3D drug distribution in CSF. Indeed, microdialysis allows the determination of the absolute concentration of a drug (i.e., a contrast agent) as a function of time in a specific area while MRI allows 3D determination of its relative concentration as a function of time.

To gain further insight in the CSF ventricular distribution of MTX we set up a rabbit model with administration of Gd-DOTA as a surrogate marker for MTX and microdialysis in the $3^{\text {rd }}$ ventricle with concurrent brain MRI acquisition in different areas of the cerebral CSF to generate CSF gadolinium concentrations in the $3^{\text {rd }}$ ventricle, lateral ventricles and magna cisterna.

MTX pharmacokinetics was studied using the same animal model after $3^{\text {rd }}$ intraventricular administration and compared with intralumbar administration and a CSF PBPK model was developed to estimate MTX distribution in the CSF of the different cerebral ventricles. 


\subsection{Chemicals}

Methotrexate (MTX - Mylan, France) and gadolinium chelate (Gd-DOTA - gadoteric acid: Dotarem, Guerbet, France) were used as the substance of interest and theophylline (Sigma, France) as an internal standard of the microdialysis technique. All reagents were of analytical grade.

\subsection{In vivo study design}

\subsubsection{Animals}

The study was performed according to a protocol approved by the Local Committee of Laboratory Investigation and Animal Care of our institution and achieved in accordance with the rules and guidelines concerning the care and the use for laboratory animal experiments (agreement n B35-238-21).

In a preliminary systemic study, 18 animals received methotrexate by intravenous route at the following doses: $2.5,5$ and $10 \mathrm{mg}(\mathrm{n}=6$, respectively). The CSF experiment was performed on 25 rabbits. Methotrexate intrathecal pharmacokinetic experiment was performed on 19 rabbits divided into two groups after intrathecal lumbar space administration $(5 \mathrm{mg}, \mathrm{n}=11)$ or $3^{\text {rd }}$ intrathecal ventricular space administration (5 mg, $\mathrm{n}=8)$.

Gadolinium $3^{\text {rd }}$ intrathecal ventricular pharmacokinetics experiment was performed on six rabbits after Gd-DOTA administration $(100 \mu \mathrm{g})$, and three of them had a simultaneous MRI recording.

\subsubsection{Experimental protocol}


All animals were sedated with an IM injection of xylazine $\left(1 \mathrm{mg} \cdot \mathrm{kg}^{-1}\right)$. The general anesthesia was induced with an IV bolus injection of $3 \mathrm{mg}^{\mathrm{kg}}{ }^{-1}$ propofol emulsion (Propofol Fresenius $10 \mathrm{mg} / \mathrm{ml}$ ) through a catheter inserted in marginal vein of the ear, and was maintained by infusion of propofol $\left(0.5 \mathrm{mg} \cdot \mathrm{kg}^{-1} \cdot \mathrm{min}^{-1}\right)$. Propofol infusion was continued during MRI experiments to avoid any movement during the MRI acquisitions.

\subsubsection{Intrathecal lumbar space}

After blunt dissection, a small laminectomy with the removal of a piece of ligamentum flavum was performed at L6-L7 level. The insertion of intrathecal catheter was achieved under visual control by a modified Seldinger technique.

In the first step, a puncture of the dura mater was performed with the needle of a seldicath (arterial catheter set, $1 \mathrm{~mm}$ external diameter). Then, the stainless steel guide wire was advanced through the needle over $6 \mathrm{~cm}$ into the intrathecal space. By sliding it over the guide wire, the needle was removed.

A silicone ureter catheter (0.028 Inch, Rush, France) was advanced along the guide wire. After removal of the guide wire, the intrathecal microdialysis probe was inserted. 
After incision of the skin on the top of the skull, a trepanation was performed at $2 \mathrm{~mm}$ posterior of the bregma and on the mid-sagittal suture. The guide cannula of the MAB6-14-2 probe was inserted in the third ventricle and anchored to the skull with dental cement. Then the microdialysis probe was introduced in the $3^{\text {rd }}$ intrathecal ventricular space.

For methotrexate experiment, a venous catheter was inserted in the left jugular vein for blood sampling. Blood samples were collected before injection and at 2, 5, 10, 20, 30 min, every 15 min until 60 min, every 30 min until 120 min and every 60 min until $240 \mathrm{~min}$.

\subsection{In vivo data acquisition}

\subsubsection{Microdialysis}

- Technical conditions :

Microdialysis was performed using a CMA 102 microinjection pump coupled to a MAB6-100-4 microdialysis probe (membrane length $4 \mathrm{~mm}$, shaft length $100 \mathrm{~mm}, 0.5$ $\mathrm{mm}$ outer diameter, molecular weight cut-off $5 \mathrm{kDa}$ ) for intrathecal lumbar administration and MAB6-14-2 (membrane length $2 \mathrm{~mm}$, shaft length $14 \mathrm{~mm}, 0.5 \mathrm{~mm}$ outer diameter, molecular weight cut-off $5 \mathrm{kDa}$ ) for intrathecal ventricular administration (Microbiotech, Stockholm, Sweden). MAB6-14-2 probe is a specific device designed as Y-port allowing probe insertion and injection of a solution at the very end of the probe membrane. Dialysates were collected using a CMA 142 microfraction collector (CMA Microdialysis, Solna, Sweden). Ringer's lactate solution 
$\left(\mathrm{NaCl} 6 \mathrm{~g} \cdot \mathrm{L}^{-1}, \mathrm{KCl} 0.4 \mathrm{~g} \cdot \mathrm{L}^{-1}, \mathrm{CaCl}_{2} \cdot 2 \mathrm{H}_{2} \mathrm{O} \quad 0.27 \mathrm{~g} \cdot \mathrm{L}^{-1}\right.$, sodium lactate $3.20 \mathrm{~g} \cdot \mathrm{L}^{-1}$, potassium phosphate $0.1 \mathrm{~g} \cdot \mathrm{L}^{-1}, \mathrm{pH}$ 7.2) was used as perfusion fluid during the microdialysis experiments.

- microdialysis calibrations :

During the experiments, microdialysis probes were perfused at $1 \mu \mathrm{l} \cdot \mathrm{min}^{-1}$ with a solution of theophylline (300 $\mu \mathrm{g} \cdot \mathrm{ml}^{-1}$ in a Ringer's lactate solution as an internal standard of the technique). Retrodialysis using theophylline as internal standard (IS) was applied to calibrate the microdialysis probes. This calibration technique is based on the principle that the relative loss $(R L)$ of an internal standard, added to the perfusate, is related to the relative recovery $(R R)$ of the substance of interest $(\mathrm{SI}$, methotrexate and gadolinium). We have tried to use, as an internal standard, folic acid which has a chemical structure very close to MTX (in order to have a RL close to the RR of MTX) but it was not possible to analyze it with the same method in a same run with MTX.

We found that theophylline (that is very hydrophilic drug) could be analyzed simultaneously with MTX. Theophylline had a RL around 0.20 (i.e., $20 \%$ ) around twice-higher that the RR of MTX (around 0,10). The difference between RL and RR led us to use a correction factor which was determined in vitro for each probe in a MTX concentration range from 0,1 to $10 \mathrm{mg} / \mathrm{ml}$ before the in vivo experiment.

Given that we validated theophylline as calibrator for MTX, we also used it for GdDOTA microdialysis with the same procedure (with the use of a correction factor determined in vitro for each probe in a Gd-DOTA concentration range from 0,002 to $0,5 \mathrm{mg} / \mathrm{ml})$

- Sampling schedule : 
After probe insertion in the intrathecal space, an in vivo equilibration with determination of relative loss $(R L)$ of internal standard ( $n=5$ for each probe tested) was performed over a period of 45 min before drug administration (either MTX or GdDOTA). During the experiment, after drug administration, RL was determined in each sample to correct dialysate concentrations at each time point as described previously [27].

For the methotrexate study, a collection interval of 1 min during the first 10 min of experiment, of $5 \mathrm{~min}$ during $60 \mathrm{~min}$ and of $10 \mathrm{~min}$ during the further experiment allowed sampling of 1,5 and $10 \mu$ of dialysate, respectively.

For the gadolinium study, a collection interval of 5 min during $60 \mathrm{~min}$ and of $10 \mathrm{~min}$ until 180 min was applied during the MRI acquisition. Owing to the high sampling frequency in the in vivo experiments, an accurate collection of micro-volume dialysates was achieved by immersion of the prolongator of the outlet tubing of microdialysis probe into 100 or $200 \mu$ l of a mobile phase solution.

- Microdialysis testing of the probes:

Before and after in vivo implantation, the probes were tested in vitro in order to verify the lack of significant deterioration by comparison with RL of internal standard [28].

\subsubsection{MRI images acquisition}


All MRI experiments were performed using a $4.7 \mathrm{~T}$ imaging spectrometer dedicated to small animal (47/40 USR Bruker Biospec), a BGA26 gradient system $(100 \mathrm{mT} / \mathrm{m})$ and "ParaVision 4.0" software (Bruker Biospin MRI, Wissembourg, France). A linear birdcage coil of $196 \mathrm{~mm}$ inner diameter [emission] and a custom-made circular surface coil of $25 \mathrm{~mm}$ diameter [reception] were used for these acquisitions.

Several $T_{1}$-weighted images were acquired using a $3 \mathrm{D}$ gradient echo sequence (FLASH 3D) and the following acquisition parameters for a total acquisition time of five minutes: TR/TE $=15 / 6 \mathrm{~ms}, \theta=30^{\circ}$, a field of view of $45^{\star} 45^{\star} 20 \mathrm{~mm}^{3}$ and a matrix of $256^{\star} 256^{*} 32$ (in-plan resolution of $176 * 176 \mu \mathrm{m}^{2}$ ), a slab thickness of $20 \mathrm{~mm}$ and a slice thickness of $625 \mu \mathrm{m}$.

A reference image was obtained before the intrathecal administration of Gd-DOTA. Images acquisition was then repeated during and over 180 minutes after the administration of Gd-DOTA, in synchronization with the microdialysis protocol of the dialysate sampling.

\subsection{Drug quantification methods}

\subsubsection{Chromatographic analysis}

Methotrexate quantification in intrathecal lumbar or cerebral dialysates and in plasma samples was carried out using a high-pressure liquid chromatographic method.

Aliquots of $20 \mu \mathrm{l}$ of the dialysate dilution were immediately injected onto the chromatographic system. This consisted of a Waters 2489 UV detector $(\lambda=274 \mathrm{~nm}$, $\lambda=307 \mathrm{~nm}$ for theophylline and methotrexate, respectively), a Waters Model 600 
pump, a Waters Model 717 automatic injector and a Waters Empower-Pro data acquisition system (Waters Assoc., Milford, MA, USA). The analytical chromatographic column was a Lichrocart-Lichrospher RP-B Merck cartridge (length $125 \mathrm{~mm}$, internal diameter $3 \mathrm{~mm}$ ). The flow rate was $0.5 \mathrm{ml} \cdot \mathrm{min}^{-1}$, and the temperature was maintained at $30^{\circ} \mathrm{C}$. The mobile phase consisted of a mixture of acetonitrile and pH 5, $0.05 \mathrm{M} \mathrm{KH}_{2} \mathrm{PO}_{4}$ (10:90).

Methotrexate was extracted from plasma according to a previously published method following modifications [29]. Briefly, $1 \mathrm{ml}$ of methanol was added to $200 \mu \mathrm{l}$ plasma samples. After centrifugation (10 min at 20,000 g) and evaporation, $200 \mu \mathrm{l}$ of mobile phase and $200 \mu \mathrm{l}$ of dichloromethane-dissolved residue, $50 \mu \mathrm{l}$ were injected onto the chromatographic system. This consisted of a Waters Model 600 pump, a Waters Model 2475 automatic injector coupled with Beam boost UVE ${ }^{\circledR}$ LC Tech (LC Technology International, Clearwater, Florida) and a Waters Empower-Pro data acquisition system (Waters Assoc., Milford, MA, USA).

The chromatography was performed on a $250 \mathrm{~mm} \times 4 \mathrm{~mm}, 5 \mu \mathrm{m}$, Discovery ${ }^{\circledR} \mathrm{C} 18$ Supelco ${ }^{\circledR}$ column (Sigma-Aldrich, St Quentin Fallavier, France) at $45^{\circ} \mathrm{C}$. Elution was performed using a gradient of solvent $\mathrm{A}\left(0.1 \mathrm{M} \mathrm{KH}_{2} \mathrm{PO}_{4}, \mathrm{pH} 5\right.$ and acetonitrile 97:3) and solvent $B(\mathrm{CH} 3 \mathrm{CN})$ from $0 \% \mathrm{~B}$ to $15 \% \mathrm{~B}$ for $15 \mathrm{~min}$ at a flow rate of $1 \mathrm{ml}^{-\mathrm{min}^{-1}}$ and 8 min of equilibration. Briefly after elution from HPLC column, methotrexate passed thought the beam boost cell and was oxidized to form fluorescent products, which were detected by fluorescence detector (excitation and emission wavelength of the fluorescence detector were set at 360 and $458 \mathrm{~nm}$, respectively). 
Gadolinium quantification in intrathecal cerebral dialysates was carried out using ICPMS (7500ce ICP-MS, Agilent technologies). Briefly, we used a Scott-type spray chamber with a nebulizer microflow set at $100 \mu \mathrm{l} \cdot \mathrm{min}^{-1}$, the flow of the peristaltic pump was $0.3 \mathrm{ml} \cdot \mathrm{min}^{-1}$, the spray-chamber temperature was set at $+2^{\circ} \mathrm{C}$ and the $\operatorname{argon}$ carrier gas flow was 15 L. $\mathrm{min}^{-1}$. Indium 115 was used as internal standard and the calibration curve achieved in $1 \% \mathrm{HNO}_{3}$ and $0.5 \% \mathrm{HCl}$ ranged from 0.1 to $50 \mathrm{fg} \cdot \mathrm{ml}^{-1}$.

\subsubsection{MRI calculation of gadolinium CSF concentrations}

Gd-DOTA is a MRI $T_{1}$ contrast agent, modifying the $T_{1}$ value of a tissue or a specific part of the brain, resulting in signal intensities increase on $\mathrm{T}_{1}$-weighted MR images. After Gd-DOTA intrathecal administration, the $T_{1}$ value of ventricle is modified as:

$$
T_{1_{(c)}}=\frac{1}{\frac{1}{T_{1_{(c=0)}}}+r_{1} \times c}
$$

where $r_{1}$ is the relaxivity of Gd-DOTA and $c$ its local concentration in the ventricle. $T_{1_{(c=0)}}$ is the reference $T_{1}$ value of the ventricle, before Gd-DOTA intrathecal administration.

The local Gd-DOTA concentration, at a time $t$, is then function of $r_{1}, T_{1_{(c=0)}}, r_{S_{0}}$, and the MRI acquisition parameters $\theta$ and TR, as:

$$
c=f\left(r_{1}, T_{1_{(c=0)}}, r_{S_{0}}, \theta, T R\right)
$$

where $r_{S_{0}}$ is the ratio between the reference signal intensity $\left(S_{0}\right)$ measured in the ventricle on the reference MR image, $\theta$ is the flip-angle and the signal intensity $\left(S_{t}\right)$ 
measured in this ventricle at a time $t$, measured on the corresponding MR image acquired at time $t$ :

$$
r_{S_{0}}=\frac{S_{0}}{S_{t}}
$$

For the calculation of local CSF gadolinium concentrations, signal intensities were measured from the MR images in four regions of interest [ROI] in the brain CSF: $3^{\text {rd }}$ ventricle corresponding to the Gd-DOTA administration site, right and left lateral ventricles and cisterna magna. Equations 2 and 3 were used with the following parameters: $r_{1}=3 \mathrm{~L} \cdot \mathrm{mmol}^{-1} \cdot \mathrm{s}^{-1}, T_{1_{(c=0)}}=3.5 \mathrm{~s}, \theta=30^{\circ}$ and TR $=15 \mathrm{~ms}[30-31]$.

Local CSF Gd-DOTA concentrations $\left[\mathrm{mmol} \cdot \mathrm{ml}^{-1}\right]$ calculated for each time $t$ allowed plotting the kinetics of gadolinium concentrations decay versus time for each ROI and each animal.

Before in vivo experimentations, this model was validated from additional MRI acquisitions and signal intensities measurements made on water/Gd-DOTA solutions with various Gd-DOTA concentrations $\left(0,0.1,0.5,1,2,4\right.$ and $\left.6 \mathrm{mg} \cdot \mathrm{ml}^{-1}\right)$. Results gave the local gadolinium concentration in each phantom with a maximum standard deviation of $5 \%$ (data not shown).

\subsubsection{Pharmacokinetic analysis}

A compartmental analysis using the software package WinNonlin Pro (Pharsight, USA) was applied to intrathecal concentrations after intrathecal ventricular and intrathecal lumbar administration; to systemic concentration after systemic administration. A non- 
compartmental analysis was applied to systemic concentration after intrathecal ventricular and intrathecal lumbar administration.

The calculated parameters are the area under concentration-time curves calculated to infinity $\left(A \cup C_{0-\infty}\right)$, volume of distribution of the central compartment $\left(\mathrm{V}_{1}\right)$ and at steady state (Vss), CLE defined as the elimination clearance, CLI defined as the intercompartmental distribution clearance, and distribution $\left[T_{1 / 2} \alpha\right]$ and elimination halflive $\left(T_{1 / 2} \beta\right)$.

To our knowledge, there is currently no rabbit PBPK model describing the drug pharmacokinetics in CSF brain ventricles. The PBPK model was built with ASCLXtrem® software (The AEgis Technologies Group Inc., Huntsville, AL). The equations used for the systemic pharmacokinetic part of the model have been described by Bruyère et al. [32] and the model for the CSF ventricle pharmacokinetics has been specifically developed. Briefly, the mass balance differential equations follow the principles shown below:

- Non-eliminating tissues:

$$
V_{T} * \frac{d C_{T}}{d t}=Q_{T} * C_{A}-Q_{T} * C V T
$$

where $Q$ is blood flow $(\mathrm{L} / \mathrm{h}), \mathrm{C}$ is concentration (mg.L-1), $\mathrm{V}$ is volume $(\mathrm{L}), \mathrm{T}$ is tissues, $\mathrm{A}$ is arterial, $\mathrm{V}$ is venous, CVT $=\mathrm{CT} / \mathrm{Kp}$, where $\mathrm{Kp}$ is tissue to plasma partition coefficient of the compound.

- Eliminating tissues:

$$
V_{T} * \frac{d C_{T}}{d t}=Q_{T} * C_{A}-Q_{T} * C V T-\text { Clint } * C V T
$$


- where CLint is the intrinsic clearance of the compound (L.h-1).

- Cerebral ventricles:

$V_{v} * \frac{d C_{v}}{d t}=D *$ Cin $-D * C v-$ Clvtoblood $* C v$

Where $v$ represents a ventricle, $D$ the CSF flow, CLvtoblood is the rate of the passage of the compound in the blood (L.h-1) and Cin the concentration entered in ventricle (dose/Volume-third ventricle at the beginning).

Model parameters were estimated from the experimental data using the Nelder-Mead algorithm module.

The classical physiological data required for a PBPK model (blood flow and volume of the different organs, unbound fraction and efflux parameters) were issued from the literature [33-35], and the volume of each brain ventricle which was not known in rabbits was determined experimentally by MRI (Table $1 \mathrm{~A})$. To humanize the model, we used CSF flow and volumes of cerebral ventricles from the literature [36-37]. MTX parameters determined using the rabbit model were not modified or optimized with in vivo data from literature. A MTX dose of $1 \mathrm{mg}$ administered in CSF as a bolus was used in order to compare with human data in the literature.

The physicochemical parameters (log P, pKa, HBD and PSA) of MTX were from the literature and are presented in Table 1B [39-44].

Both MTX and Gd-DOTA were studied in solution and as a consequence no dissolution equation was included in the model. Briefly, the PBPK model for the brain CSF and systemic pharmacokinetics is described in Figure 1. The model differs from that of Bruyère et al. [32] in that the gastrointestinal tract was not divided in sections. 
Simulations were performed using a standard rabbit (3 kg body weight; cardiac blood flow $530 \mathrm{ml} \cdot \mathrm{min}^{-1}$ ). Organ volumes were expressed as a percentage of bodyweight and organ blood flows as a percentage of the cardiac blood [33]. The assumptions for the model were: (a) transport between CSF ventricles and between cisterna magna occurred via CSF flow, (b) systemic intercompartmental transport occurred via the blood, (c) drug concentrations in effluent blood and blood within tissues were equal, (d) there was instantaneous equilibrium between tissue and blood within the tissue (flow-limited model as previously described, 36-37), (e) only unbound drugs were eliminated, (f) the model was based on a well-stirred model for all organs ( $g$ ) the unbound fraction in the CSF ventricles is 1.

The CSF ventricle PBPK model was firstly built with Gd-DOTA data to determine the rates of transfer between ventricles. As Gd-DOTA and MTX showed very similar properties in terms of CSF ventricular disposition in the $3^{\text {rd }}$ ventricle (see in vivo results), the rates of transfer of Gd-DOTA were used for MTX in ventricles. Systemic PBPK parameters for MTX (Kp and transfer rates) and transfer rates from CSF ventricles to blood were then estimated. Diffusion parameters $(\mathrm{Kp})$ in each organ were estimated and optimized using Poulin's algorithms [40,43].

\subsubsection{Statistical analysis}

All data are reported as mean $\pm S D$. A $p$ value less than 0.05 was considered as statistically significant.

\section{RESULTS}




\subsection{Methotrexate intrathecal pharmacokinetics}

The CSF disposition of MTX was biphasic with a very significant inter-individual variability after lumbar CSF administration compared to the ventricular administration (Figure 2A-2C and Table 1). Indeed, a twice-higher variability in AUC (CV of $80 \%$ vs. $45 \%)$ was evidenced. Such a high variability after lumbar administration was noticed in the same model with local anesthetic drugs [45].

Pharmacokinetic differences appeared only in the distribution of MTX with higher volumes $\left(\mathrm{V}_{1}\right.$ and $\left.\mathrm{Vss}\right)$ for the ventricular administration as a result of a higher CSF volume in this area.

\subsection{Methotrexate plasma pharmacokinetics}

The data obtained after IV administration showed that the systemic pharmacokinetics was linear in the range 2, 5 to $10 \mathrm{mg}$ (Table 2 and Figure 3). MTX showed a biphasic disposition with apparent distribution and elimination half-lives around $7 \mathrm{~min}$ and 30 min respectively.

The plasma MTX concentrations after ventricular and lumbar intrathecal administration showed very similar profiles with an apparent elimination half-life which was around seven times higher than that after IV dosing (Figure 2B-2D and Table 3). Such a phenomenon may result from a rate-limiting absorption from MTX from CSF to the blood as a result of its hydrophilicity.

The limiting absorption from CSF into the blood is also illustrated by the low plasma-toCSF AUC ratio that was around $10^{-3}$ after CSF administration. This low exchange 
between CSF and plasma compartment is also shown by the low brain extracellular fluid to plasma ratio in rats after IV administration (around $5 \%$, [46]).

\subsection{Gadolinium intrathecal pharmacokinetics}

The CSF disposition of Gd-DOTA in the $3^{\text {rd }}$ ventricle (Figure 4) was clearly biphasic with apparent distribution and elimination half-lives very closed to that of MTX (Table 1). Indeed, mean distribution half-lives were $6.4 \mathrm{~min}$ and $7.6 \mathrm{~min}$ and mean elimination half-lives were $93 \mathrm{~min}$ and $90 \mathrm{~min}$ for gadolinium and MTX, respectively.

The MRI experiment allowed the calculation of time-course of Gd-DOTA in the different brain CSF areas ( $3^{\text {rd }}$ ventricle, lateral ventricles and cisterna magna) from signal intensities (Figure 5). While the time-course in the lateral ventricles did not display any measurable delay in obtaining the maximal concentration, the Tmax in the cisterna magna (Figure 6) was around 45 min suggesting a slow diffusion within brain CSF from $3^{\text {rd }}$ ventricle to cisterna magna.

\subsection{PBPK of MTX in CSF}

The brain ventricle part of the PBPK model was built and validated from calculated and observed MRI concentrations of Gd-DOTA to fit diffusion coefficients and rates of transfer of Gd-DOTA between each ventricle. The mean MRI determined and the predicted concentrations of Gd-DOTA are presented in Figure 7. All CV of estimated PBPK parameters (calculated standard error divided by the estimated value) were 
lower than $23 \%$ and the final log-likelihood value was higher than 100 , suggesting a suitable model (initial value close to 0 , final value of 118).

From the validated CSF Gd-DOTA PBPK model, a whole MTX PBPK model (CSF and systemic) was created by implementation with systemic clearance organs. PBPK parameters of Gd-DOTA in the ventricles were used for MTX assuming that Gd-DOTA and MTX had very similar pharmacokinetics in the $3^{\text {rd }}$ ventricle (i.e., the relative contribution of clearance and distribution were similar for both molecules as described in section 3.3).

Predicted MTX concentrations in the $3^{\text {rd }}$ ventricle showed a good agreement with observed MTX concentrations for both 2.5 and $5 \mathrm{mg}$, confirming that Gd-DOTA properties in the ventricles could be transposed to MTX (only data for the $5 \mathrm{mg}$ dose are showed in Figure 8). Indeed, the predicted AUC in the $3^{\text {rd }}$ ventricle (182 min.mg.ml' $\left.{ }^{1}\right)$ was close to the mean observed AUC $\left(229+/-102\right.$ min.mg.ml $\left.{ }^{-1}\right)$ for the $5 \mathrm{mg}$ administration. CVs were higher for MTX estimated parameters than for Gd-DOTA parameters (CVs between 22 and $51 \%$ ) but this increase was expected as prediction for MTX used estimated parameter of Gd-DOTA. Thus, as CVs were cumulative, the MTX CVs were higher (final log likelihood value remained high at 108).

Predicted parameters allowing plasma MTX concentration estimation after administration in the $3^{\text {rd }}$ ventricle were calculated from our observed data after IV and intrathecal administrations (Figure 9). It should be noticed that two animals (observations 1 and 2) had a different plasma pharmacokinetics with higher Cmax and lower Tmax. The AUC of the predicted curve (160 min. $\mu \mathrm{g} \cdot \mathrm{ml}^{-1}$ ) was close to the measured AUC (207 +/- 72 min. $\left.\mathrm{gg} \cdot \mathrm{ml}^{-1}\right)$. Furthermore, predicted Tmax (102 min) and 
Cmax $\left(0.67 \mu \mathrm{g} \cdot \mathrm{ml}^{-1}\right)$ were close to the measured values $(85+/-69 \mathrm{~min}$ and $0.93+/-$ $0.67 \mu \mathrm{g} \cdot \mathrm{ml}^{-1}$, respectively). These results suggested that our PBPK model should be relevant for MTX intrathecal administration in rabbit.

From this validated model, simulations with different dosing schedule (infusion alone or bolus + infusion) were undertaken to estimate concentrations in the $3^{\text {rd }}$ and lateral ventricles, and in cisterna magna. After an intrathecal bolus, predicted plasma Cmax and Tmax were $6.65 \times 10^{-4} \mathrm{mg} \cdot \mathrm{ml}^{-1}$ and $102 \mathrm{~min}$, respectively. After an intrathecal infusion of $5 \mathrm{mg}$ for one hour, predicted plasma Cmax and Tmax were $6.29 \times 10^{-4}$ $\mathrm{mg} \cdot \mathrm{ml}^{-1}$ and $135 \mathrm{~min}$, respectively. There was no difference in term of plasma concentration but the Tmax was slightly higher after infusion.

Predicted Cmax in the cisterna magna were also very close between bolus and infusion (28.2 versus $26.6 \mathrm{mg} \cdot \mathrm{ml}^{-1}$ ) but the difference is much higher in the $3^{\text {rd }}$ and lateral ventricles. Even if concentrations were definitely lower after infusion with a plateau lasting $30 \mathrm{~min}$, the Cmax in the cisterna magna stayed very close. The exposure in the $3^{\text {rd }}$ ventricle was also closed for both dosing schedule (predicted AUC in the $3^{\text {rd }}$ ventricle was $181 \mathrm{~min} \cdot \mathrm{mg} \cdot \mathrm{ml}^{-1}$ after bolus injection and was $175 \mathrm{~min} \cdot \mathrm{mg} \cdot \mathrm{ml}^{-1}$ after infusion when observed AUC was $229+/-102$ min.mg. $\mathrm{ml}^{-1}$ ). In the cistern magna, the exposure was comparable for both dosing as predicted AUC after bolus was 7560 min.mg.ml ${ }^{-1}$ and 7270 min.mg. $\mathrm{ml}^{-1}$ after infusion.

By using the humanized PBPK model, predicted concentrations were obtained after 1 mg bolus dosing (Figure 11) for purpose of comparison with data in the literature obtained in humans after administration in a lateral ventricle

\section{DISCUSSION}


The experimental study of the drug distribution in cerebral CSF is necessary because the current literature lacks detailed informations on the precise drug distribution within CSF ventricles. Moreover, clinicians should be aware that direct administration in CSF might lead to a rather limited and non-uniform drug distribution.

Interestingly, a microdialysis study of the longitudinal spread of intrathecal opioids along the spinal canal in a pig model has shown that slow intrathecal infusion $(0.02$ to $1 \mathrm{ml} . \mathrm{hrs}^{-1}$ ) led to a quite limited drug distribution within CSF for both hydrophilic and lipophilic drugs $[47,48]$. For the lowest drug infusion rate, most of the drug spread within only $1 \mathrm{~cm}$ of the site of administration with a steep gradient.

Indeed basic mechanisms should be considered to explain why the drug distribution within CSF is limited: i) the brownian motion affecting all molecules is too slow to account for drug spread greater than several hundred microns, ii) the kinetic energy impulsed by the injection depending on the speed of injection [volume per unit of time] and on the diameter of the catheter which is low by intrathecal dosing especially when infusion are used iii) CSF motion whose rate and extent governs the drug spread is low and iv] drug clearance depending on physico-chemical properties.

The non-uniform drug distribution within the subarachnoid space precluding the attainment of clinically effective concentrations within all CSF is also a major drawback of the intrathecal drug administration. The main reason is that mixing in CSF is slower than mixing in blood as a result as a huge difference in fluid circulation time which is around $1 \mathrm{~min}$ in blood [blood volume / cardiac output] compared to 6 to $8 \mathrm{hrs}$ in CSF (CSF volume / CSF bulk flow rate) [49]. 
For these reasons, even if a drug is administered as a constant infusion, it will not be possible to obtain a uniform concentration throughout CSF from ventricle to the lumbar level whether the drug is administered in the ventricle or at the lumbar level.

Moreover, drug clearance from CSF affects drug diffusion throughout the CSF, and depends on three main processes: i) CSF bulk flow through the normal pathway of CSF absorption (depending on the rate of CSF production and volume of CSF compartment), ii) drug transfer from CSF to neural parenchymal tissues and choroid plexus and iii) drug vascular absorption into brain capillaries and to the systemic circulation.

The bulk flow component of the clearance is not dependent on the physico-chemical properties of the drug and can be estimated from drugs that have negligible membrane permeability and remain predominantly in the extracellular space. In a non-human primate model, this clearance component has been estimated to $4 \mu \mathrm{l} \cdot \mathrm{min}^{-1}$ using EDTA-Ca [50]. However, drug transfer into neural tissue and vascular absorption are mainly dependent on lipophilicity so that lipophilic drugs as BCNU and thiotepa have clearance (145 and $\left.113 \mu \mathrm{l} \cdot \mathrm{min}^{-1}\right)$ that are much higher than those of hydrophilic drugs such as cytosine arabinosine, MTX and hydroxyurea $\left(22,16\right.$ and $\left.14 \mu \mathrm{l} \cdot \mathrm{min}^{-1}\right)$. Hence, for lipophilic drugs, local CSF administration as a bolus dose is not an effective way for drug delivery to distant subarachnoid sites so that ventricular administration will not allow achieving therapeutic levels at distance in the lumbar sac.

The ratio of elimination clearance (CLE) to the distribution clearance (CLI) of MTX in the ventricular and lumbar areas was different indicating that the relative contribution of each process to the overall disposition was different. Indeed, the contribution of the 
elimination clearance to the overall disposition in the ventricular area is higher $(63 \%)$ than in the lumbar area (46\%). It has been shown in a series of homologous drugs that the contribution of the elimination process increased with hydrophilicity and became prevalent for the most hydrophilic compounds [45].

As a result of differences in clearance and distribution processes between the ventricular and lumbar area, the MTX exposition was around 3-times lower in the ventricular area (Table 1).

In our model, the elimination clearance of MTX after intracerebral ventricular administration $\left(27+/-16 \mu \mathrm{l} \cdot \mathrm{min}^{-1}\right)$ was in accordance with previous data in a monkey model $\left(C L=16 \mu l \cdot \mathrm{min}^{-1}\right)[50]$. The MTX elimination clearance was slightly, but not significantly higher, than Gd-DOTA clearance $\left(22+/-16 \mu l \cdot \mathrm{min}^{-1}\right)$ in accordance with the higher hydrophilicity of this latter compound.

Given the relative values of the micro-constants of elimination $\left(\mathrm{K}_{10}\right)$ and distribution constants $\left(\mathrm{K}_{12}\right.$ and $\left.\mathrm{K}_{21}\right)$ for both drugs, the similarity in MTX and Gd-DOTA intrathecal profiles in CSF (Figure 2A and Figure 4) is not unexpected. Moreover, the ratios of elimination clearance (CLE) to the distribution clearance (CLI) of MTX and Gd-DOTA in the $3^{\text {rd }}$ ventricle were very close (63 and 66\%) indicating that the relative contributions of each process to the overall disposition were similar. Based on the similarity in the processes governing the disposition of these two drugs, the 3D distribution of Gd-DOTA within lateral ventricles and cisterna magna obtained by MRI would be a surrogate marker for MTX disposition within ventricles allowing a better understanding of the factors that govern the diffusion of this drug in these CSF spaces. However, Gd-DOTA would not be a suitable tracer for more lipophilic anticancer agents, and a different Gd-chelate with a higher lipophilicity would be necessary. 
The DOTA-Gd concentrations in brain ventricles obtained from MRI experiments and the similar properties of DOTA-Gd and MTX allowed the validation of a ventricular PBPK model and its transposition to MTX to simulate MTX concentrations in the different ventricles. There are very few PBPK models for MTX in literature, one for human embryo set up for purpose of toxicity and one for blood and malignant effusion fluid distribution [51-52]. Very recently, a system-based pharmacokinetic model was developed for studying the brain parenchyma distribution of MTX in rats after IV administration and its extrapolation to other species [36].

The predicted plasma terminal half-life seemed to be shorter compared to most of the individual profiles, suggesting that the model could be improved (Figure 9). In the ventricular part of the model (Figure 8), the difference is certainly due to the fact that two rabbits had a different kinetic behavior as their terminal phase decreased more rapidly compared to the others. As no clear reason could be highlighted during our in vivo experiments to exclude these two animals, both of them were used for in vivo and predicted parameter determination to keep the same bias even if it increased the variability in the parameters evaluation.

Simulations with different dosing schedule (infusion alone or bolus + infusion) were performed to estimate concentrations in the $3^{\text {rd }}$ and lateral ventricles, and in cisterna magna to estimate potential clinical effects given that the target levels of MTX in CSF of patients are around $10^{-6} \mathrm{M}$ or $4.5 \times 10^{-4} \mathrm{mg}^{-1} \mathrm{ml}^{-1}[4,19-20]$ in agreement with the commonly acknowledged concentration of $10^{-6} \mathrm{M}$ required to obtain the killing effect of MTX on tumor cells that has been estimated in animal models [22-23]. 
We have built a humanized PBPK model by using volume and flow of human CSF (Table 1). The levels of predicted concentrations obtained after $1 \mathrm{mg}$ bolus dosing (Figure 11) were in the order of magnitude of the CSF levels measured in humans after administration in a lateral ventricle $[49,53]$. However, the comparison should be made with caution because the sites of administration and of sampling in humans were not the same as in our model. Indeed, in humans the ventricle administration is usually performed in one of the lateral ventricles. The fact that the predicted levels in the cisterna magna were higher than measured levels in the lumbar CSF [53] is not unlikely since the distance from the site of injection is higher and may increase the concentration gradient. The comparison with the human studies also showed that our predicted elimination half-life was longer than observed in the above mentioned clinical studies. A difference in efflux/uptake transporter expression between species may explain such differences in MTX disposition in CSF. Indeed, in non-human primates, probenecid has been shown to modulate the MTX levels in ventricular CSF [54].

By changing the way of administration (infusion instead of bolus), the MTX exposures were similar in the $3^{\text {rd }}$ and lateral ventricles for each schedule but with a much higher Cmax after bolus dosing. Similarly, these two different dosing schedules led to a similar exposure (both in AUC and Cmax) in the cisterna magna with a slightly higher Tmax (around 30\%) for the infusion mode. However, the cisterna magna exposure was much higher than that in the $3^{\text {rd }}$ and lateral ventricles.

These simulations showed that the dosing schedule influenced the exposure level in the $3^{\text {rd }}$ and lateral ventricles with no difference in the cisterna magna. Depending on the objective to be attained (high Cmax for drug with concentration-dependent 
pharmacological activity or prolonged exposure for drug with time-dependent pharmacological activity) specific schedules using bolus or infusion may be chosen.

This rabbit PBPK model should be next extended to another animal species, and incorporate influx/efflux transport parameters to allow a relevant translation to humans, and the design of optimized dosing regimen. Moreover, such a model would also be helpful for the study of the CNS distribution and further brain parenchyma distribution of protein therapeutics used for neurological conditions (e.g., stroke, neurodegenerative diseases and brain tumors). Indeed, the direct intrathecal administration would be a useful and perhaps ideal route of administration given the difficulty for these drugs to by-pass the blood-brain barrier after IV dosing [55].

As limitations of this study, it should be noticed that the experimental conditions may differ from real-life situations as a result of potential impact of general anesthesia, rabbit positioning and probe implantation on CSF flow.

The influence of general anesthesia on CSF flow should be considered, as in previous studies [47, 48] since our rabbits were first sedated with xylazine and then under general anesthesia using propofol throughout the MRI experiment. The choice of propofol, that is quite unusual for a general anesthesia in animals, was based on the fact that general anesthesia with propofol avoids anormal movements during the anesthesia that would preclude the MRI experiments. Moreover, data in the literature show that there are no significant changes in CSF flow induced by general anesthesia either using halothane, fentanyl or propofol [56-58].

Body positioning has been shown to affect intracranial hydrodynamics and hemodynamics in humans. Using phase-contrast MRI, cyclic variations in CSF flow 
have been registered showing that CSF flow is not steady but varies over the cardiac circle [59]. Difference in CSF flow has also been shown between subjects in sitting or upright position as a result of reduced amounts of blood and CSF residing in their intracranial compartments in the upright position [60]. We found no specific informations on the influence of animal positioning on the CSF flow. However, the animals were ventrally positioned in the MRI tube so that the impact should be the same as it could be observed on a animal resting ventrally in our other experiments (outside the MRI). However, as patients may have different posture (standing, sitting or recumbent), the influence of the posture on the diffusion of drugs within the cranial CSF could occur, and deserves to be investigates.

To our knowledge, there is no data on the influence of a microdialysis probe insertion on CSF flow. However, its impact could arise from an influence of the probe on the hydrostatic pressure that could result from its insertion. This impact should not be a confounding factor since the rate of choroidal CSF formation is rather insensitive to hydrostatic pressure changes in the CSF [61].

Microdialysis measures only unbound drug while MRI measures total drug. Eventhough methotrexate binds to albumin in plasma (around 60\%), its binding in CSF can be considered as negligible because CSF is a fluid that does not contain so much proteins with a CSF/serum ratio for albumin of around $0,6 \%$ in healthy subjects [62]. Based on these data, we can consider that MTX in CSF is essentially unbound and that the MRI measurement of MTX in CSF reflects the microdialysis estimation. However, in case of a variation in permeability of the BBB, an increase in CSF albumin may occur that could introduce a bias between microdialysis and MRI measurements. This could occur if the study was performed in an animal model with leptomeningeal metastases. 
Limitations of our study may also arise from the fact that microdialysis concentrations were only measured at the $3^{\text {rd }}$ ventricle and used in combination with MRI for extrapolation to lateral ventricles and to the cisterna magna. An other limitation of the PBPK modeling should also be done, especially for the translation to humans. Indeed, for drugs which are substrate of influx/efflux transporters, such as MTX, interspecies differences in expression and localization should be taken into account.

In conclusion, the present study showed that the combination of local CSF microdialysis and CSF MRI acquisition with a PBPK model could be a useful methodology to estimate the drug diffusion within CSF ventricles after direct brain CSF administration. Such a methodology would be of interest to clinicians for a rationale determination and optimization of drug dosing parameters in the treatment of leptomeningeal metastases.

\section{Acknowledgements}

We are most grateful to the PRISM core facility (Biogenouest@, UMS Biosit, Université de Rennes 1 - Campus de Villejean, 35043 Rennes Cedex, France) for its technical support.

\section{References}

1. Khasraw M, Posner JB. Neurological complications of systemic cancer. Lancet Neurol. 2010; 912:1214-27. 
2. Chamberlain MC, Sloan A, Vrionis F; Cancer Care Ontario Practice Guidelines Initiative's Neuro-Oncology Disease Site Group. Systematic review of the diagnosis and management of malignant extradural spine cord compression: The Cancer Care Ontario Practice Guidelines Initiative's Neuro-Oncology Disease Site Group. J Clin Oncol. 2005; 23:7750-1.

3. Gleissner B, Chamberlain MC. Neoplastic meningitis. Lancet Neurol. 2006; 5:44352.

4. Shinoura N, Tabei Y, Yamada R, Saito K, Takahashi M. Continuous intrathecal treatment with methotrexate via subcutaneous port: implication for leptomeningeal dissemination of malignant tumors. J Neurooncol. 2008; 87:309-16.

5. Bomgaars L, Geyer JR, Franklin J, Dahl G, Park J, Winick NJ, Klenke R, Berg SL, Blaney SM. Phase I trial of intrathecal liposomal cytarabine in children with neoplastic meningitis. J Clin Oncol. 2004; 22:3916-21.

6. Jabbour E, O'Brien S, Kantarjian H, Garcia-Manero G, Ferrajoli A, Ravandi F, Cabanillas M, Thomas DA. Neurologic complications associated with intrathecal liposomal cytarabine given prophylactically in combination with high-dose methotrexate and cytarabine to patients with acute lymphocytic leukemia. Blood. 2007; 109:3214-8.

7. Sung C, Blaney SM, Cole DE, Balis FM, Dedrick RL. A pharmacokinetic model of topotecan clearance from plasma and cerebrospinal fluid. Cancer Res. 1994; 54:5118-22.

8. Thompson PA1, Berg SL, Aleksic A, Kerr JZ, McGuffey L, Dauser R, Nuchtern JG, Hausheer F, Blaney SM. Plasma and cerebrospinal fluid pharmacokinetic study of BNP1350 in nonhuman primates. Cancer Chemother Pharmacol. 2004; 53:527-32.

9. Egorin MJ, Zuhowski EG, McCully CM, Blaney SM, Kerr JZ, Berg SL, Balis FM. Pharmacokinetics of intrathecal gemcitabine in nonhuman primates. Clin Cancer Res. 2002; 8:2437-42. 
10. Kerr JZ, Berg SL, Dauser R, Nuchtern J, Egorin MJ, McGuffey L, Aleksic A, Blaney S. Plasma and cerebrospinal fluid pharmacokinetics of gemcitabine after intravenous administration in nonhuman primates. Cancer Chemother Pharmacol. $2001 ; 47: 411-4$.

11. Sun JM, Nam MH, Chung JY, Im B, Lee SY, Suh YL, Ahn JS, Park K, Ahn MJ. Safety and pharmacokinetics of intrathecal administration of pemetrexed in rats. Cancer Chemother Pharmacol. 2011; 68:531-8.

12. Blaney SM, Heideman R, Berg S, Adamson P, Gillespie A, Geyer JR, Packer R, Matthay K, Jaeckle K, Cole D, Kuttesch N, Poplack DG, Balis FM. Phase I clinical trial of intrathecal topotecan in patients with neoplastic meningitis. J Clin Oncol. 2003; 21:143-7.

13. Gururangan S, Petros WP, Poussaint TY, Hancock ML, Phillips PC, Friedman HS, Bomgaars L, Blaney SM, Kun LE, Boyett JM. Phase I trial of intrathecal spartaject busulfan in children with neoplastic meningitis: a Pediatric Brain Tumor Consortium Study (PBTC-004). Clin Cancer Res. 2006; 12:1540-6.

14. Bernardi RJ, Bomgaars L, Fox E, Balis FM, Egorin MJ, Lagattuta TF, Aikin A, Whitcomb P, Renbarger J, Lieberman FS, Berg SL, Blaney SM. Phase I clinical trial of intrathecal gemcitabine in patients with neoplastic meningitis. Cancer Chemother Pharmacol. 2008; 62:355-61.

15. Rubenstein JL, Fridlyand J, Abrey L, Shen A, Karch J, Wang E, Issa S, Damon L, Prados M, McDermott M, O'Brien J, Haqq C, Shuman M. Phase I study of intraventricular administration of rituximab in patients with recurrent CNS and intraocular lymphoma. J Clin Oncol. 2007; 25:1350-6.

16. Chamberlain MC, Johnston SK, Van Horn A, Glantz MJ. Recurrent lymphomatous meningitis treated with intra-CSF rituximab and liposomal ara-C. J Neurooncol. 2009; 91:271-7. 
17. Sandberg DI, Crandall KM, Koru-Sengul T, Padgett KR, Landrum J, Babino D, Petito CK, Solano J, Gonzalez-Brito M, Kuluz JW. Pharmacokinetic analysis of etoposide distribution after administration directly into the fourth ventricle in a piglet model. J Neurooncol. 2010; 97:25-32.

18. Sandberg DI, Solano J, Petito CK, Mian A, Mou C, Koru-Sengul T, GonzalezBrito M, Padgett KR, Luqman A, Buitrago JC, Alam F, Wilkerson JR, Crandall KM, Kuluz JW. Safety and pharmacokinetic analysis of methotrexate administered directly into the fourth ventricle in a piglet model. J Neurooncol. 2010; 100:397-406.

19. Mehta BM, Glass JP, Shapiro WR. Serum and cerebrospinal fluid distribution of 5-methyltetrahydrofolate after intravenous calcium leucovorin and intra-Ommaya methotrexate administration in patients with meningeal carcinomatosis. Cancer Res. $1983 ; 43: 435-8$.

20. Shapiro WR, Young DF, Mehta BM. Methotrexate: distribution in cerebrospinal fluid after intravenous, ventricular and lumbar injections. N Engl J Med. 1975; 293:161-6.

21. Blasberg RG, Patlak C, Fenstermacher JD. Intrathecal chemotherapy: brain tissue profiles after ventriculocisternal perfusion. J Pharmacol Exp Ther. 1975; 195:73-83.

22. Yen J, Reiss FL, Kimelberg HK, Bourke RS. Direct administration of methotrexate into the central nervous system of primates. Part 2: Distribution of $3 \mathrm{H}$ methotrexate after intrathecal lumbar injection. J Neurosurg. 1978; 48:895-902.

23. Kimelberg HK, Kung D, Watson RE, Reiss FL, Biddlecome SM, Bourke RS. Direct administration of methotrexate into the central nervous system of primates. Part 1: Distribution and degradation of methotrexate in nervous and systemic tissue after intraventricular injection. J Neurosurg. 1978; 48:883-94. 
24. Azeredo FJ, Dalla Costa T, Derendorf H. Role of microdialysis in pharmacokinetics and pharmacodynamics: current status and future directions. Clin Pharmacokinet. 2014 Mar;53(3):205-12.

25. de Lange EC.

Utility of CSF in translational neuroscience.

J Pharmacokinet Pharmacodyn. 2013 Jun;40(3):315-26

26. Frasca D, Dahyot-Fizelier C, Adier C, Mimoz O, Debaene B, Couet W, Marchand S. Metronidazole and hydroxymetronidazole central nervous system distribution: 1. microdialysis assessment of brain extracellular fluid concentrations in patients with acute brain injury. Antimicrob Agents Chemother. 2014;58(2):1019-23

27. Rose FX, Estebe JP, Ratajczak M, Wodey E, Chevanne F, Dollo G, Bec D, Malinovsky JM, Ecoffey C, Le Corre P. Epidural, intrathecal pharmacokinetics, and intrathecal bioavailability of ropivacaine. Anesth Analg. 2007; 105:859-67.

28. Ratajczak-Enselme M, Estebe JP, Rose FX, Wodey E, Malinovsky JM, Chevanne F, Dollo G, Ecoffey C, Le Corre P. Effect of epinephrine on epidural, intrathecal, and plasma pharmacokinetics of ropivacaine and bupivacaine in sheep. Br J Anaesth. 2007; 99:881-90.

29. Hui Li, Luo W, Zeng Q, Lin Z, Luo H, Zhang Y. Method for the determination of blood methotrexate by high performance liquid chromatography with online postcolumn electrochemical oxidation and fluorescence detection. J Chromatogr B Analyt Technol Biomed Life Sci. 2007; 845:164-8.

30. Marques JP, Kober T, Krueger G, van der Zwaag W, Van de Moortele PF, Gruetter R.MP2RAGE, a self bias-field corrected sequence for improved segmentation and T1-mapping at high field. Neuroimage. 2010; 49:1271-81.

31. Rooney WD, Johnson G, Li X, Cohen ER, Kim SG, Ugurbil K, Springer CS Jr. Magnetic field and tissue dependencies of human brain longitudinal $1 \mathrm{H} 2 \mathrm{O}$ relaxation in vivo. Magn Reson Med. 2007; 57:308-18. 
32. Bruyère A, Declèves X, Bouzom F, Ball K, Marques C, Treton X, Pocard M, Valleur P, Bouhnik Y, Panis Y, Scherrmann JM, Mouly S. Effect of variations in the amounts of P-glycoprotein (ABCB1), BCRP (ABCG2) and CYP3A4 along the human small intestine on PBPK models for predicting intestinal first pass. Mol Pharm. 2010; 7:1596-607.

33. Lebas F, Laplace JP. Mensurations viscerales chez le lapin. I. Croissance du foie, des reins et des divers segments intestinaux. Annales de Zootechnie 21, 337347.

34. Bode U, Magrath IT, Bleyer WA, Poplack DG, Glaubiger DL. Active transport of methotrexate from cerebrospinal fluid in humans. Cancer Res. 1980; 40:2184-7.

35. Chen ML, Chiou WL. Pharmacokinetics of methotrexate and 7-hydroxymethotrexate in rabbits after intravenous administration. J Pharmacokinet Biopharm. $1983 ; 11: 499-513$.

36. Westerhout J, van den Berg DJ, Hartman R, Danhof M, de Lange EC. Prediction of methotrexate CNS distribution in different species - influence of disease conditions. Eur J Pharm Sci. 2014; 57:11-24

37. Johnson LA, Pearlman JD, Miller CA, Young TI, and Thulborn KR. MR Quantification of Cerebral Ventricular Volume Using a Semiautomated Algorithm. AJNR Am J Neuroradiol. 1993;14(6):1373-8

38. Özkan C., Kaya A., Akgül Y. Normal values of haematological and some biochemical parameters in serum and urine of New Zealand white rabbits. World Rabbit Sci. 2012, 20: 253 - 259.

39. Chen HSG, Gross JF. Physiologically based pharmacokinetic models for anticancer drugs. Cancer Chemother Pharmacol. 1979; 2:85-94. 
40. Poulin P, Krishnan K. An algorithm for predicting tissue: blood partition coefficients of organic chemicals from n-octanol: water partition coefficient data. $\mathrm{J}$ Toxicol Environ Health. 1995; 46:117-29.

41. Sangster J; A Databank of Evaluated Octanol-Water Partition Coefficients (LOG P) on Microcomputer Diskette, Sangster Res Lab 1994.

42. Hansch C, Leo A, Hoekman D. Exploring QSAR - Hydrophobic, Electronic, and Steric Constants. American Chemical Society. 1995 (book).

43. Poulin P, Theil FP. A priori prediction of tissue:plasma partition coefficients of drugs to facilitate the use of physiologically-based pharmacokinetic models in drug discovery. J Pharm Sci. 2000; 89:16-35.

44. Ogungbenro K, Aarons L. Physiologically based pharmacokinetic modelling of methotrexate and 6-mercaptopurine in adults and children. Part 1: methotrexate. J Pharmacokinet Pharmacodyn. 2014; 41:159-71.

45. Clément R, Malinovsky JM, Hildgen P, Dollo G, Estèbe JP, Chevanne F, Le Verge R, Le Corre P. Spinal disposition and meningeal permeability of local anesthetics. Pharm Res. 2004; 21:706-16.

46. de Lange EC, de Vries JD, Zurcher C, Danhof M, de Boer AG, Breimer DD. The use of intracerebral microdialysis for the determination of pharmacokinetic profiles of anticancer drugs in tumor-bearing rat brain. Pharm Res. 1995; 12:192431.

47. Ummenhofer WC, Arends RH, Shen DD, Bernards CM. Comparative spinal distribution and clearance kinetics of intrathecally administered morphine, fentanyl, alfentanil, and sufentanil. Anesthesiology. 2000; 92:739-53. 
48. Bernards CM. Cerebrospinal fluid and spinal cord distribution of baclofen and bupivacaine during slow intrathecal infusion in pigs. Anesthesiology. 2006; 105:16978.

49. Balis FM, Blaney SM, McCully CL, Bacher JD, Murphy RF, Poplack DG. Methotrexate distribution within the subarachnoid space after intraventricular and intravenous administration. Cancer Chemother Pharmacol. 2000; 45:259-64.

50. Blasberg RG, Patlak CS, Shapiro WR. Distribution of methotrexate in the cerebrospinal fluid and brain after intraventricular administration. Cancer Treat Rep. 1977; 61:633-41.

51. Verwei M, Freidig AP, Havenaar R, Groten JP. Prediction of in vivo embryotoxic effect levels with a combination of in vitro studies and PBPK modelling. J Nutr. 2006; 136:3074-8.

52. Li J, Gwilt P. The effect of malignant effusions on methotrexate disposition. Cancer Chemother Pharmacol. 2002; 50:373-82.

53. Bleyer WA, Poplack DG, Simon RM. Concentration $x$ time" methotrexate via a subcutaneous reservoir: a less toxic regimen for intraventricular chemotherapy of central nervous system neoplasms. Blood. 1978 May;51(5):835-42

54. Salzer W, Widemann B, McCully C, Adamson PC, Balis FM.

Effect of probenecid on ventricular cerebrospinal fluid methotrexate pharmacokinetics after intralumbar administration in nonhuman primates.

Cancer Chemother Pharmacol. 2001 Sep;48(3):235-40.

55. Calias P, Banks WA, Begley D, Scarpa M, Dickson P. Intrathecal delivery of protein therapeutics to the brain: A critical reassessment. Pharmacol Ther. 2014; 144:114-22.

56. Artru AA. Effects of halothane and fentanyl anesthesia on resistance to reabsorption of CSF. J Neurosurg. 1984 ; 60 : 252-6. 
57. Artru AA. Propofol Combined with Halothane or with Fentanyl/Halothane Does Not Alter the Rate of CSF Formation or Resistance to Reabsorption of CSF in Rabbits. J Neurosurg Anesthesiol. 1993, $5:$ 250-257

58. Artru AA and Momota T.Rate of CSF formation and resistance to reabsorption of CSF during sevoflurane or remifentanil in rabbits. J Neurosurg Anesthesiol. 2000;12 : 37-43.

59. Hladky SB, Barrand MA. Mechanisms of fluid movement into, through and out of the brain: evaluation of the evidence. Fluids Barriers CNS. 2014 Dec 2;11(1):26

60. Alperin N, Lee SH, Sivaramakrishnan A, Hushek SG. Quantifying the effect of posture on intracranial physiology in humans by MRI flow studies. J Magn Reson Imaging. 2005;22 : 591-6.

61. Brinker T, Stopa E, Morrison J, Klinge P. A new look at cerebrospinal fluid circulation. Fluids Barriers CNS. 2014, 11: 1-16.

62. Llorens F, Schmitz M, Gloeckner SF, Kaerst L, Hermann P, Schmidt C, Varges D, Zerr I.Increased albumin CSF/serum ratio in dementia with Lewy bodies. J Neurol Sci. 2015 Nov 15;358(1-2):398-403 


\section{Legend to Figures}

Figure 1: Schematic representation of the PBPK model built to predict the in vivo disposition of Gd-DOTA and MTX in CSF ventricles and blood in rabbit (with RVT = richly vascularized organ and PVT = poorly vascularized organ)

Figure 2: Mean (bold) and individual intrathecal and systemic concentration - time profile after $3^{\text {rd }}$ intrathecal ventricular $(A, B)$ and intrathecal lumbar $(C, D)$ administration of $5 \mathrm{mg}$ of Methotrexate in rabbit.

Figure 3: Mean (bold) and individual concentration - time profile in plasma after systemic administration of $2.5 \mathrm{mg}(\mathrm{A}), 5 \mathrm{mg}(\mathrm{B})$ and $10 \mathrm{mg}(\mathrm{C})$ of methotrexate in rabbit $(n=6)$.

Figure 4: Mean (bold) and individual intrathecal concentration - time profile after intrathecal ventricular administration of $100 \mu \mathrm{g}$ of Gd-DOTA in rabbit.

Figure 5: In vivo MRI visualization of Gd-DOTA distribution in the CSF of $3^{\text {rd }}$ ventricle and in the cisterna magna.

Figure 6: Predicted (line) and individual MRI (dots) determined concentrations of GdDOTA in cisterna magna after intrathecal administration of Gd-DOTA in the $3^{\text {rd }}$ ventricle in rabbit $(n=3)$. 
Figure 7: Predicted (lines) and mean MRI (dots) determined concentrations of GdDOTA in all ventricles and cisterna magna after intrathecal administration of GdDOTA in the $3^{\text {rd }}$ ventricle in rabbit $(n=3)$

Figure 8: Predicted (line) and individual (dots) MTX concentrations in the third ventricle after an intrathecal administration of $5 \mathrm{mg}$ in the third ventricule.

Figure 9: Predicted (line) and individual (dots) plasma concentrations of MTX after intrathecal administration of $5 \mathrm{mg}$ in the $3^{\text {rd }}$ ventricule.

Figure 10 : MTX predicted rabbit concentrations in the $3^{\text {rd }}$ ventricle, in the lateral ventricles and cisterna magna (left) and in plasma (right) after administration as intrathecal bolus of $5 \mathrm{mg}$, infusion of $5 \mathrm{mg}$ during $1 \mathrm{hrs}$ and bolus + infusion (both at $5 \mathrm{mg}$, infusion for $1 \mathrm{hrs}, 4 \mathrm{hrs}$ after bolus injection).

Figure 11 : MTX predicted human concentrations in the $3^{\text {rd }}$ ventricle and cisterna magna after administration as intrathecal bolus of $1 \mathrm{mg} \mathrm{MTX}$ after humanization of the rabbit PBPK model. 


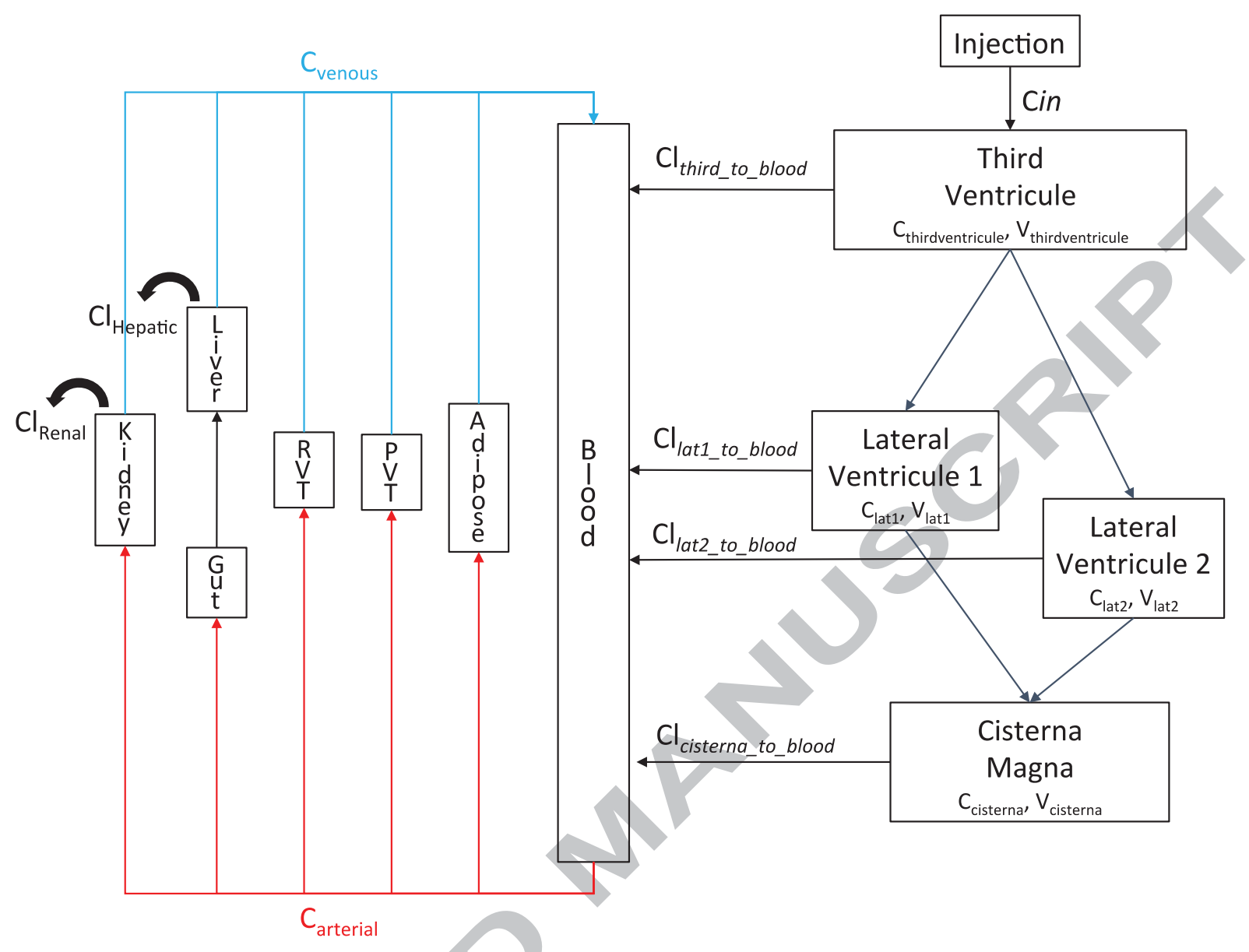


Figure 2
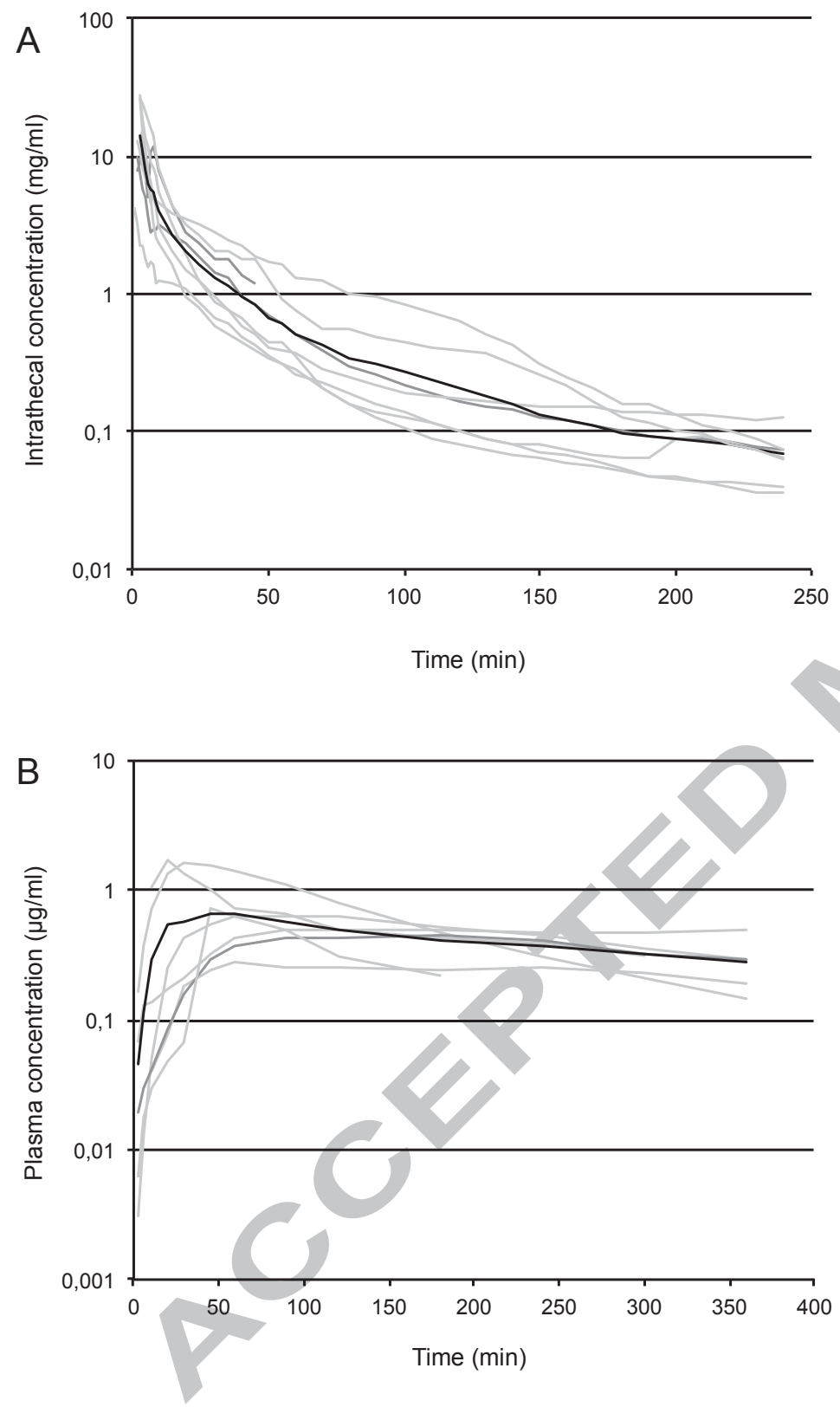
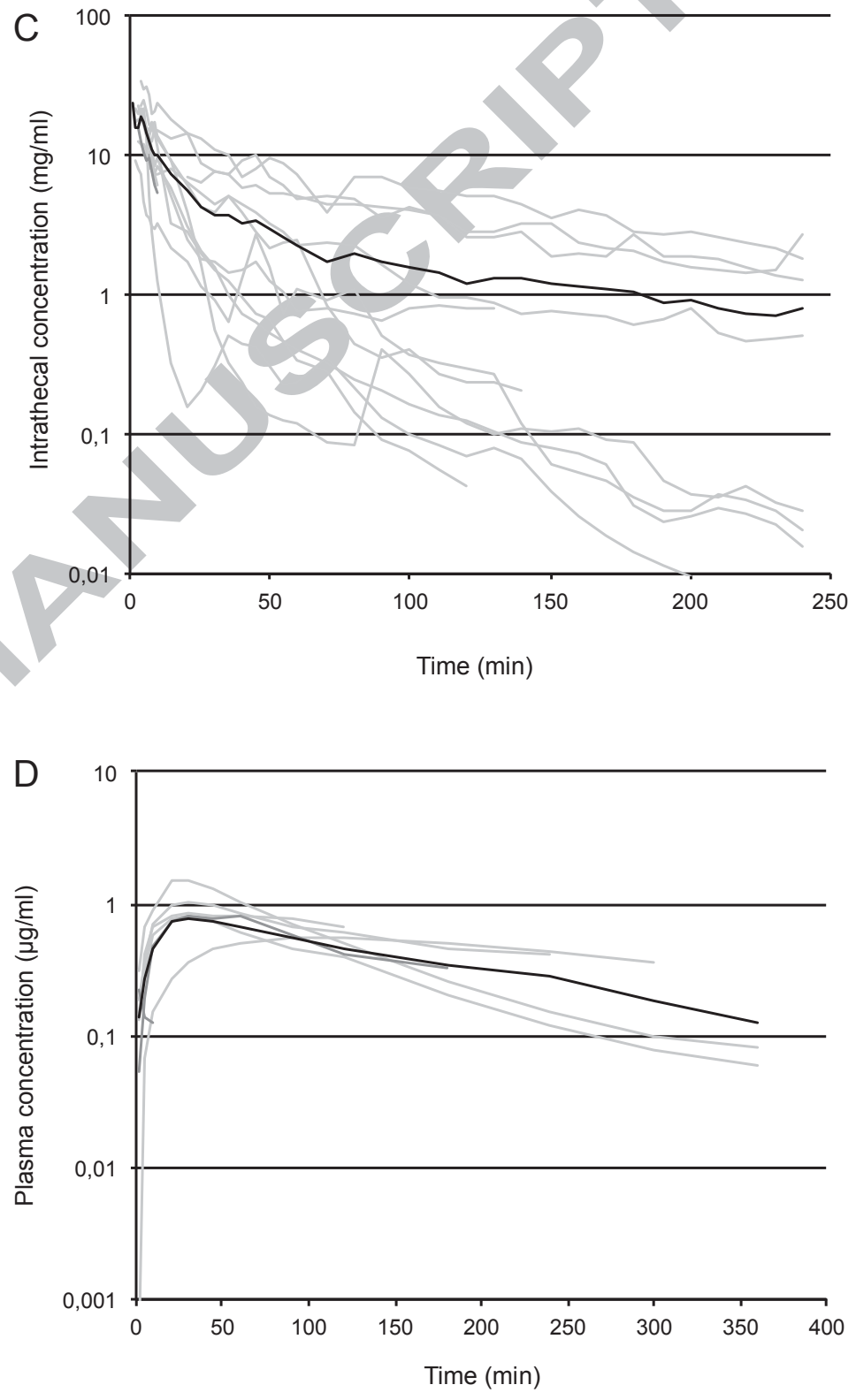
Figure 3
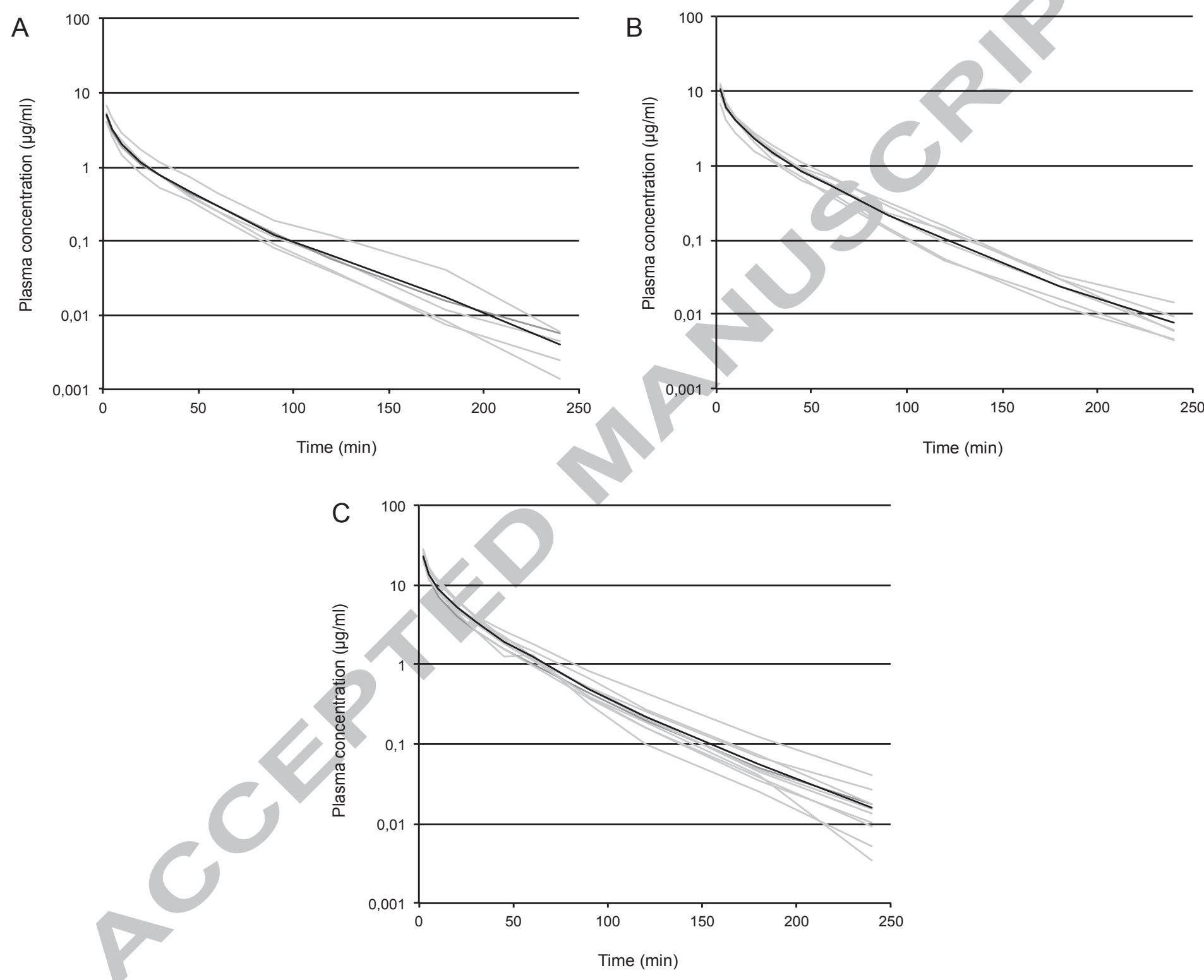
Figure 4

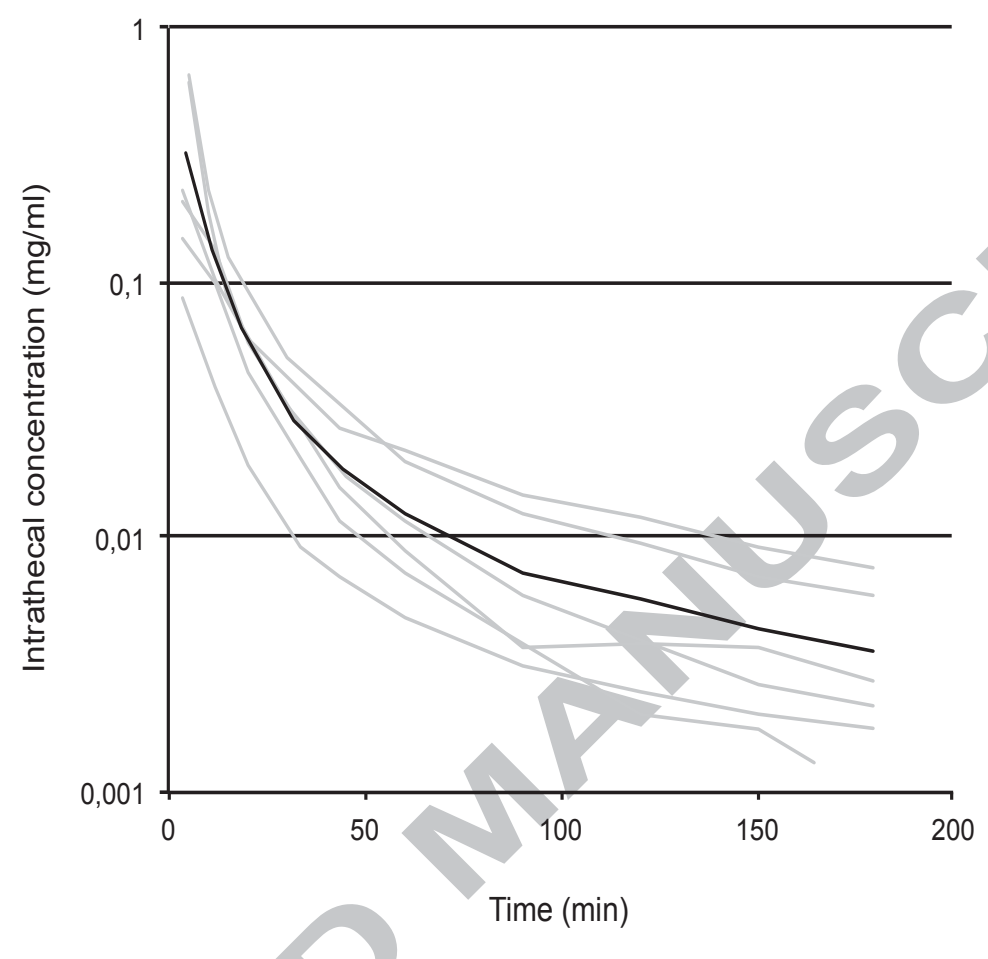




\section{Figure 5}

$3^{\text {rd }}$ ventricle
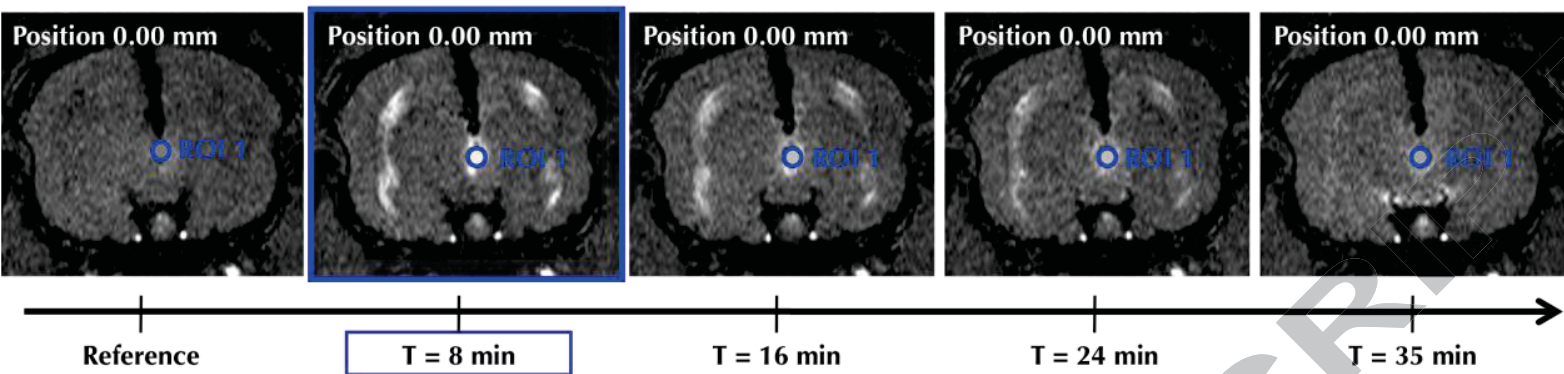

$\mathrm{T}=35 \mathrm{~min}$

Cisterna Magna

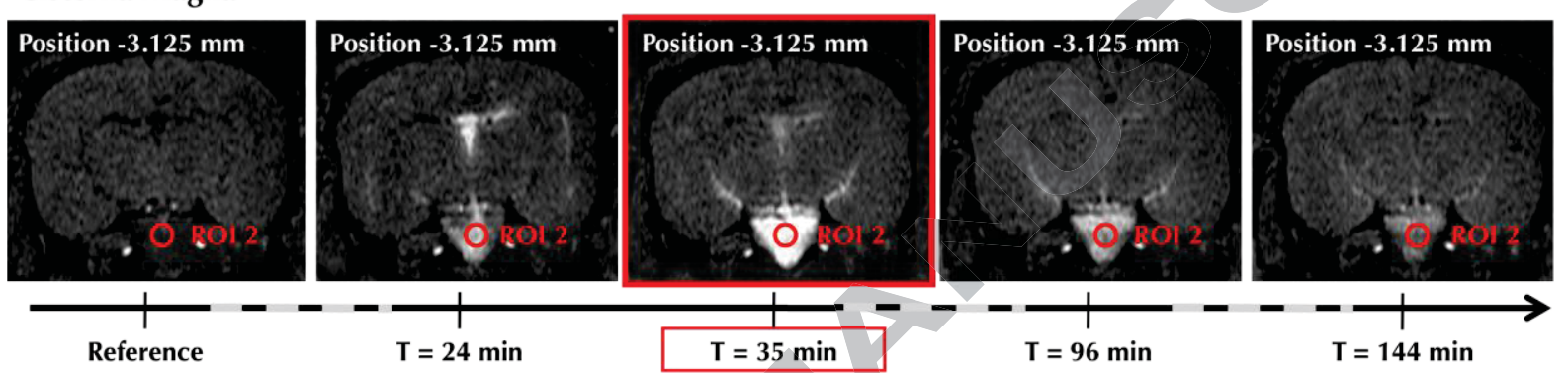


Figure 6

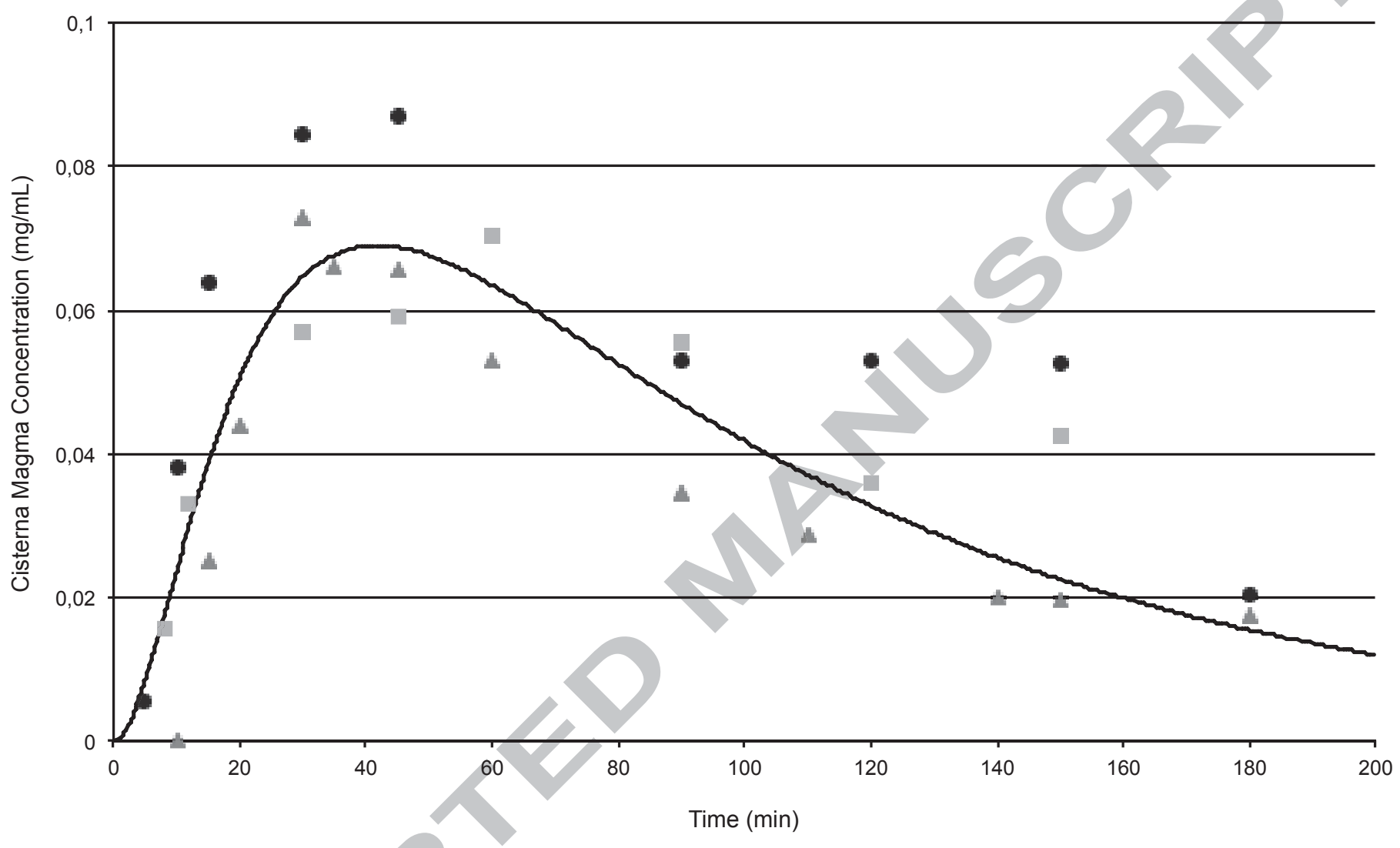




\section{Figure 7}

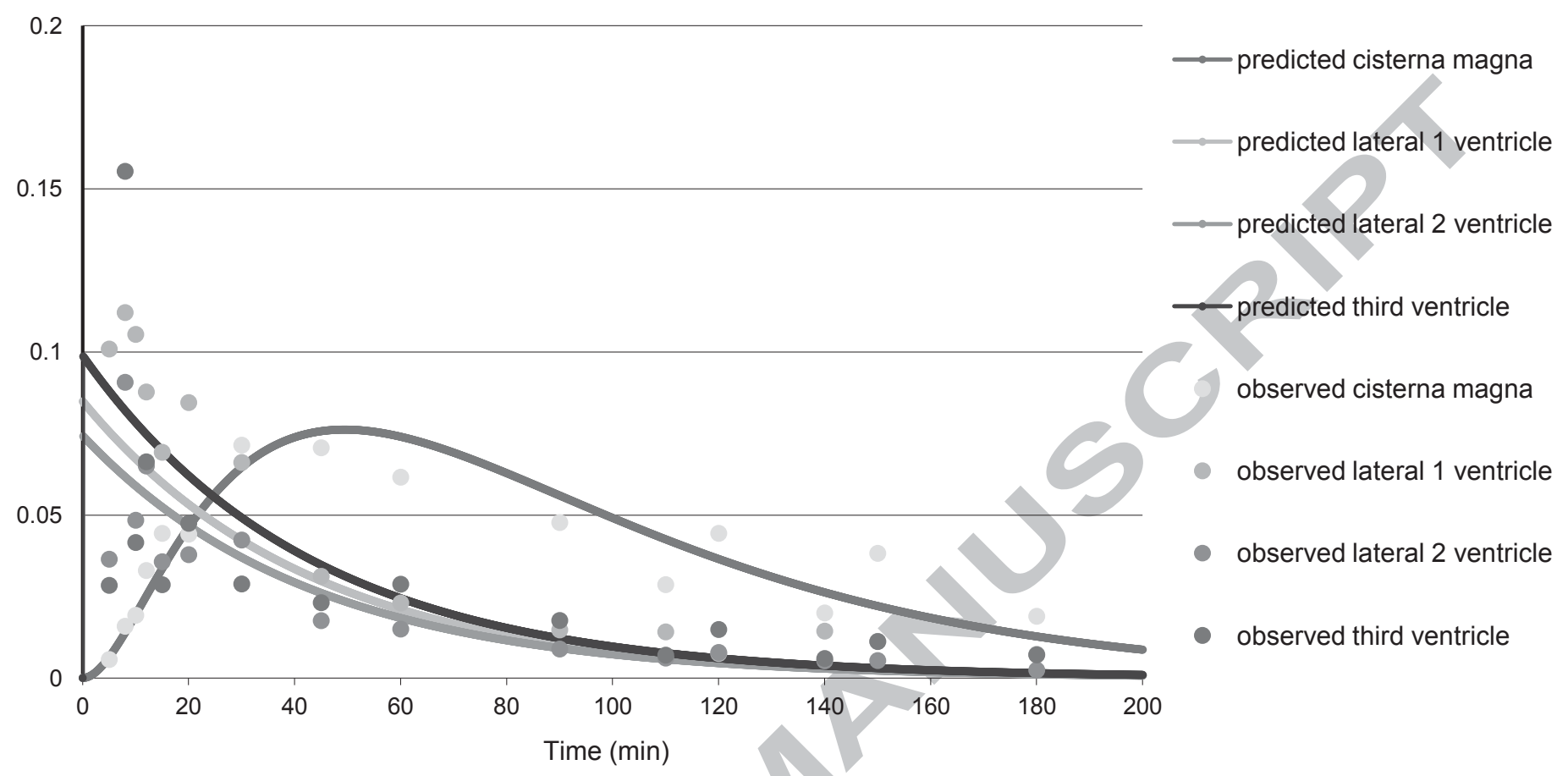


Figure 8

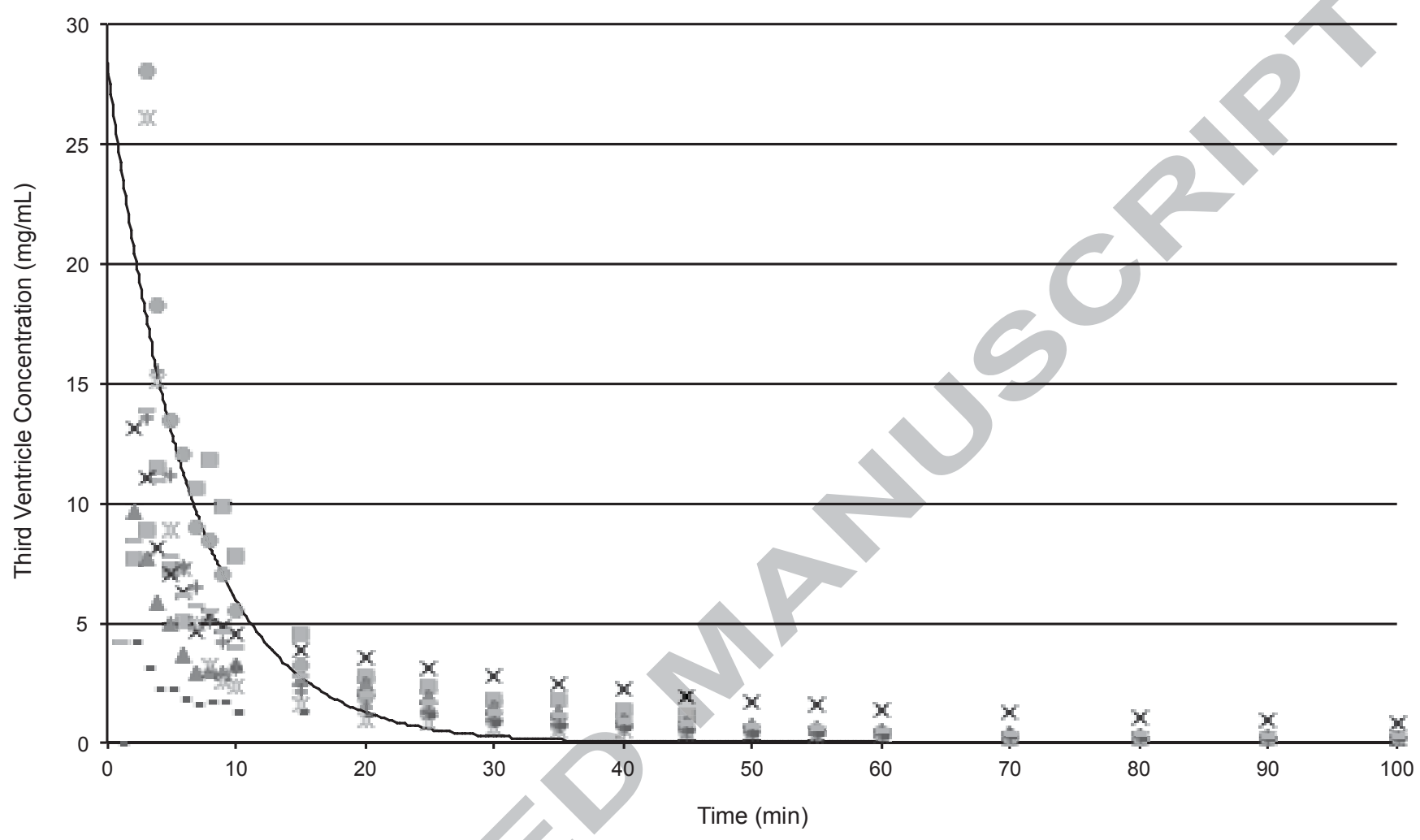


Figure 9

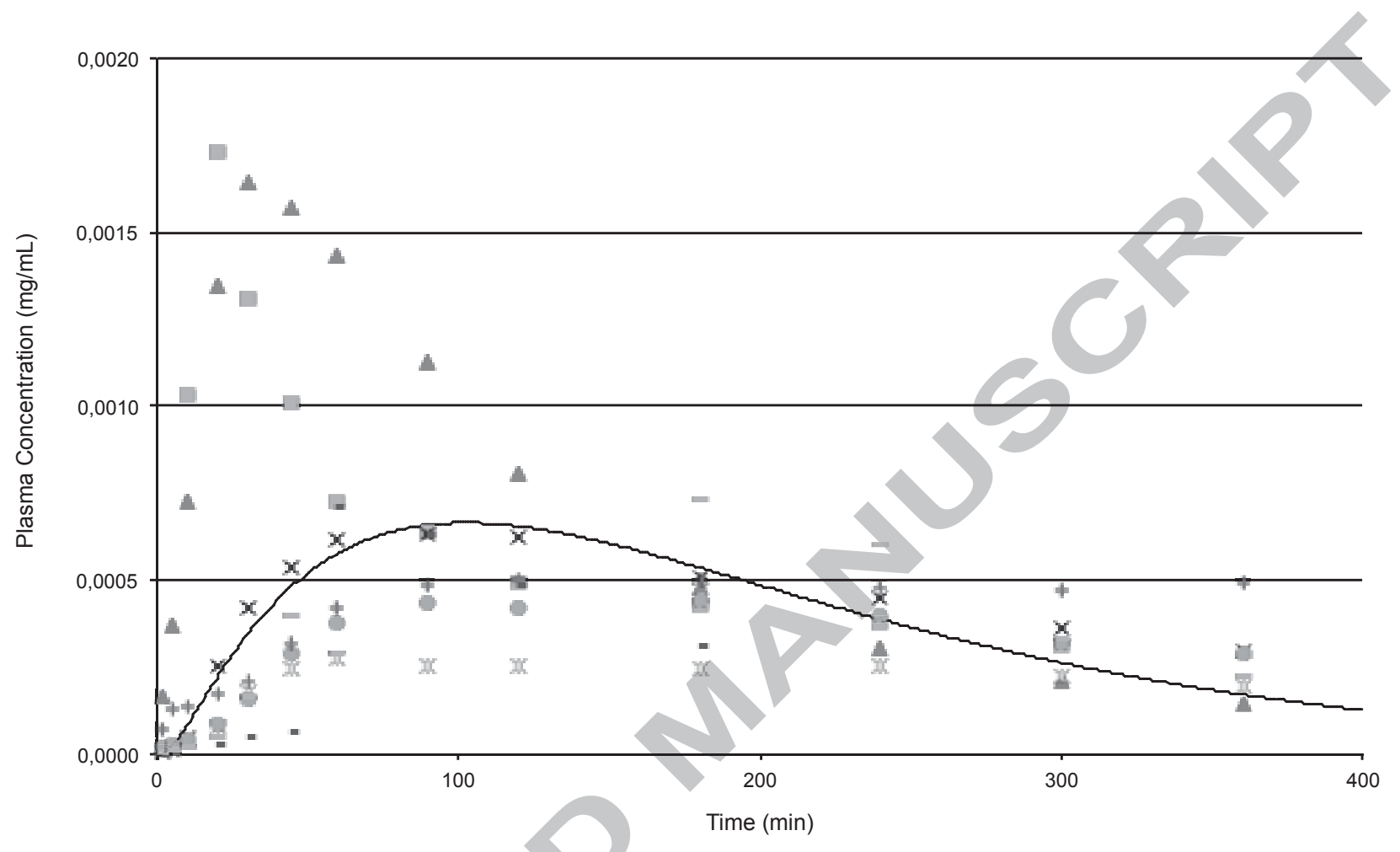




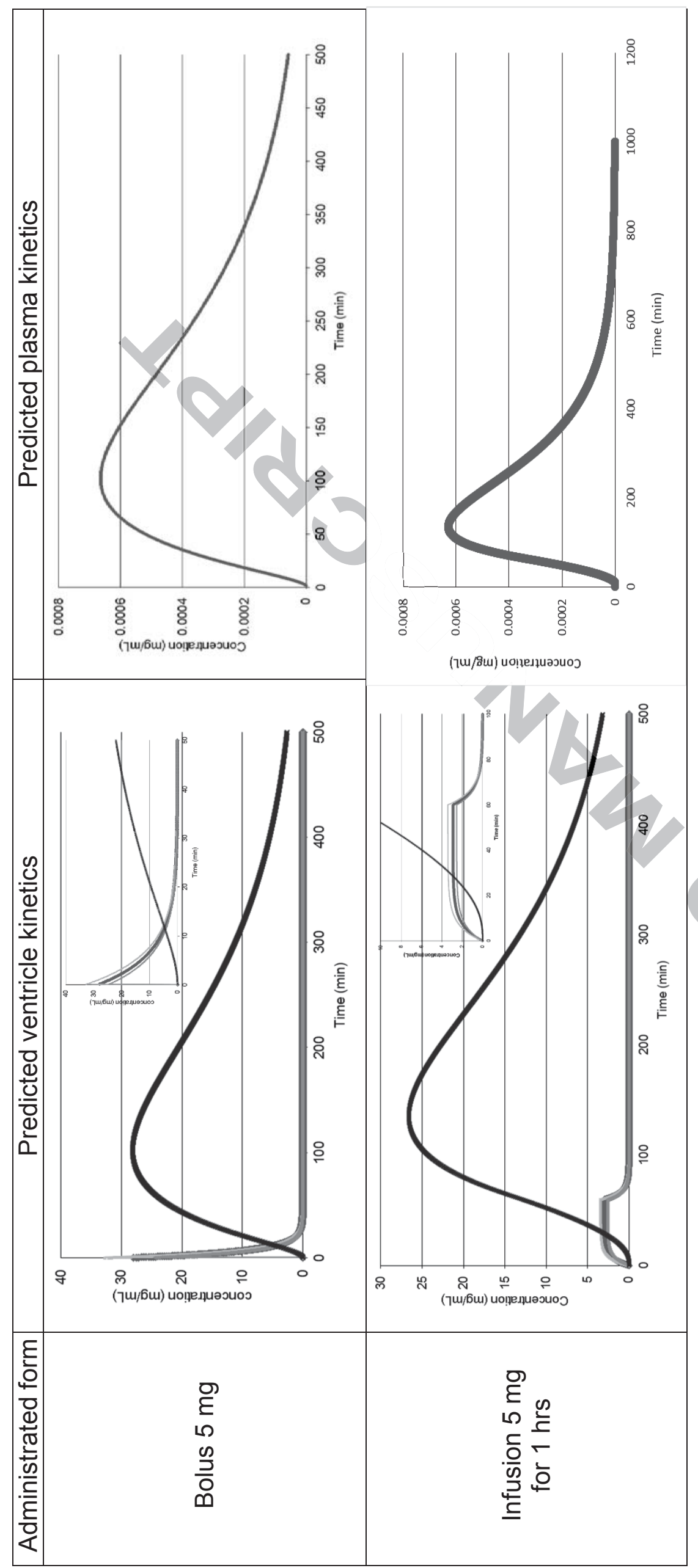




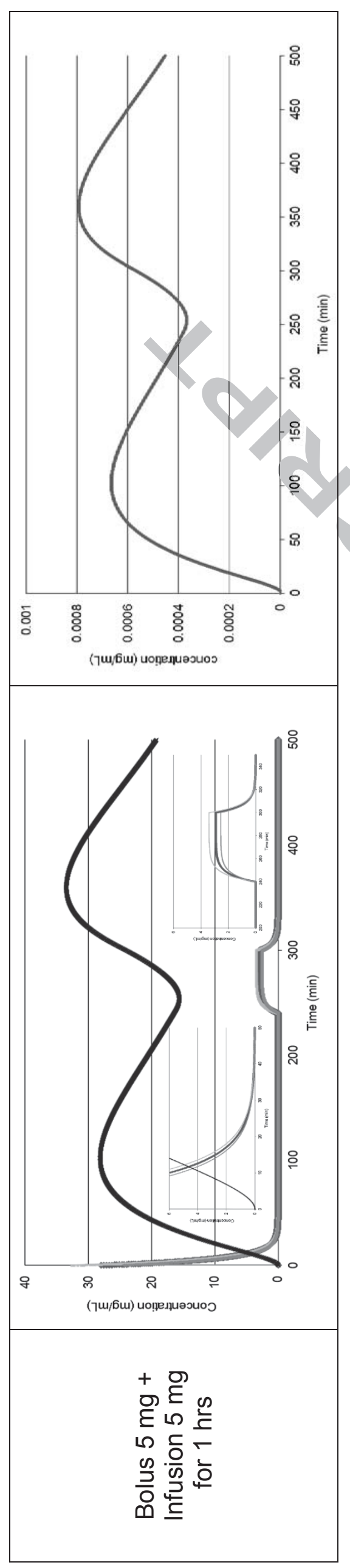


Figure 11

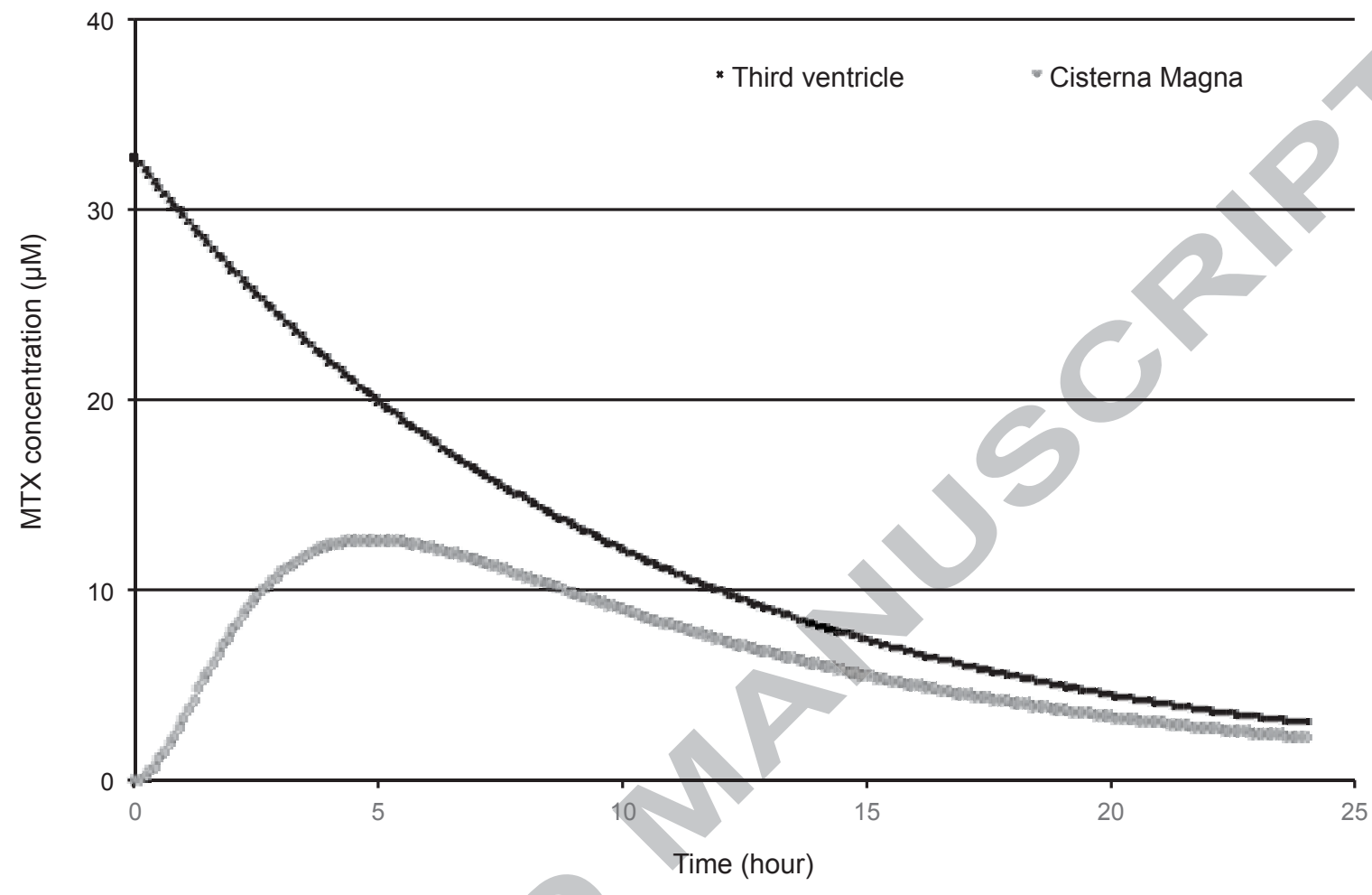


Table 1A

\begin{tabular}{|c|c|c|}
\hline Physiological parameters & Fixed values & source \\
\hline Bodyweight (kg) & 3 & Lebas and Laplace $^{33}$ \\
\hline Cardiac output $\left(\mathrm{Q}_{\text {blood }}, \mathrm{L} / \mathrm{h}\right)$ & 530 & Lebas and Laplace $^{33}$ \\
\hline CSF output (Qcsf, L/h) & $2.74161 * 10^{-2}$ & $\begin{array}{l}\text { Estimated from Gd-DOTA } \\
\text { model }\end{array}$ \\
\hline third ventricle volume & 0.0117 & MRI measure \\
\hline lateral ventricles volume & 0.040 and 0.028 & MRI measure \\
\hline deep ventricle volume & 0.083 & MRI measure \\
\hline cisterna magna volume & 0.013 & MRI measure \\
\hline liver fraction output & 0.3349 & Lebas and Laplace $^{33}$ \\
\hline Kidney fraction output & 0.1509 & Lebas and Laplace $^{33}$ \\
\hline $\begin{array}{l}\text { Poorly vascularized tissue } \\
\text { fraction output }\end{array}$ & 0.0604 & Lebas and Laplace $^{33}$ \\
\hline liver fraction volume & 0.0308 & Lebas and Laplace $^{33}$ \\
\hline Blood fraction volume & 0.056 & Lebas and Laplace $^{33}$ \\
\hline $\begin{array}{l}\text { Poorly vascularized tissue } \\
\text { fraction volume }\end{array}$ & & Lebas and Laplace $^{33}$ \\
\hline Hematocrit percentage & 0.49 & Özcan et al. ${ }^{38}$ \\
\hline Intestinal length (m) & 3 & http://www.fao.org \\
\hline Intestinal diameter & 0.01 & http://www.fao.org \\
\hline Human CSF output (mL/min) & 0.4 & \\
\hline $\begin{array}{l}\text { Human third ventricle volume } \\
(\mathrm{mL})\end{array}$ & 1.87 & Johnson et al. $1993^{36}$ \\
\hline $\begin{array}{l}\text { Human lateral ventricle volume } \\
(\mathrm{mL})\end{array}$ & 21.85 & Johnson et al. $1993^{36}$ \\
\hline $\begin{array}{l}\text { Human cisterna magna volume } \\
(\mathrm{mL})\end{array}$ & 7.5 & Westerhout et al. $2014^{37}$ \\
\hline
\end{tabular}

Rabbit volumes are expressed as a fraction of bodyweight and rabbit output as a fraction of the cardiac output 
Table 1B

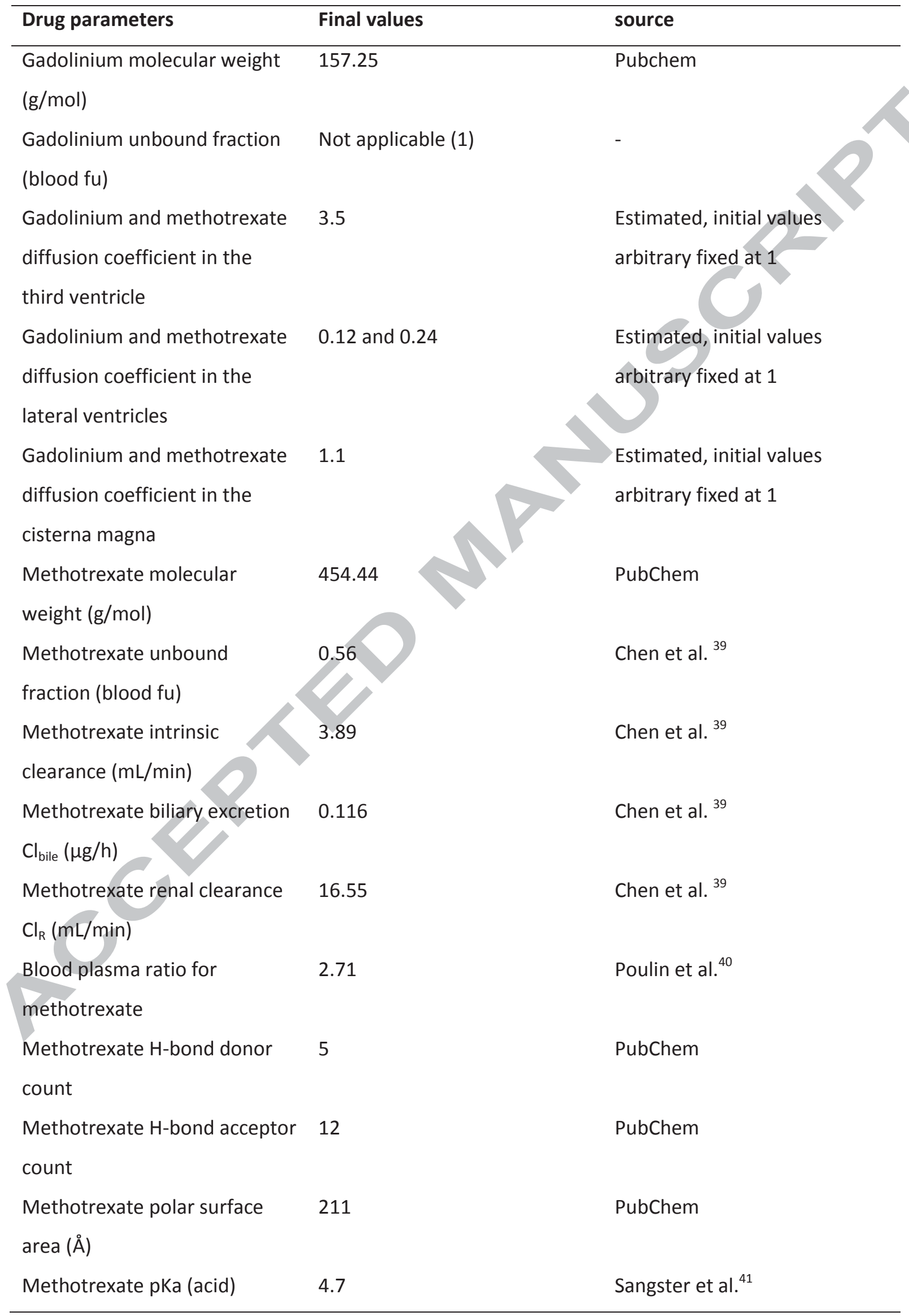




\begin{tabular}{|c|c|c|}
\hline Methotrexate LogP & -1.85 & Hansch et al. ${ }^{42}$ \\
\hline Methotrexate permeability & 0.014 & Estimated, initial value from \\
\hline from CSF to blood $\left(\mathrm{Cl}_{\text {perm }}\right)$ & & Bode et al. ${ }^{34}$ \\
\hline \multirow[t]{3}{*}{ Methotrexate liver Kp } & 0.23 & Estimated, initial values \\
\hline & & calculated using equati \\
\hline & & from Poulin et al. ${ }^{43-44}$ \\
\hline \multirow[t]{3}{*}{ Methotrexate kidney Kp } & 1.13 & Estimated, initial values \\
\hline & & calculated using equations \\
\hline & & from Poulin et al. ${ }^{43-44}$ \\
\hline \multirow[t]{2}{*}{ Methotrexate PVT Kp } & 18.8 & Estimated, initial values \\
\hline & & calculated using equations \\
\hline \multirow[t]{3}{*}{ Methotrexate RVT Kp } & 1.2 & Estimated, initial values \\
\hline & & calculated using equations \\
\hline & & from Poulin et al. ${ }^{43-44}$ \\
\hline \multirow[t]{3}{*}{ Methotrexate intestine Kp } & 1.0 & Estimated, initial values \\
\hline & & calculated using equations \\
\hline & & from Poulin et al. ${ }^{43-44}$ \\
\hline
\end{tabular}


Table 2: Systemic pharmacokinetic parameters of methotrexate after intravenous administration of $2.5 \mathrm{mg}, 5 \mathrm{mg}$ and $10 \mathrm{mg}$ of methotrexate in rabbit $(\mathrm{n}=6)$.

\begin{tabular}{|c|c|c|c|}
\hline Parameters & IV $2.5 \mathrm{mg}$ & IV 5 mg & IV $10 \mathrm{mg}$ \\
\hline CLE (ml/min) & $30.6 \pm 7.0$ & $28.4 \pm 8.9$ & $27.7 \pm 3.7$ \\
\hline $\mathrm{CLI}(\mathrm{ml} / \mathrm{min})$ & $15.4 \pm 10.0$ & $9.7 \pm 8.2$ & $9.8 \pm 3.2$ \\
\hline Vss (ml) & $820.5 \pm 165.8$ & $777.2 \pm 158.9$ & $715.0 \pm 92.3$ \\
\hline V1 (ml) & $492.6 \pm 108.7$ & $519.3 \pm 193.0$ & $469.9 \pm 79.3$ \\
\hline $\mathrm{T} 1 / 2 \propto(\mathrm{min})$ & $6.5 \pm 2.0$ & $8.8 \pm 3.2$ & $7.6 \pm 1.8$ \\
\hline $\mathrm{T} 1 / 2 \beta$ (min) & $28.5 \pm 2.5$ & $34.0 \pm 10.1$ & $28.7 \pm 3.7$ \\
\hline K10 & $0.063 \pm 0.012$ & $0.056 \pm 0.016$ & $0.060 \pm 0.008$ \\
\hline K12 & $0.033 \pm 0.023$ & $0.023 \pm 0.026$ & $0.022 \pm 0.009$ \\
\hline K21 & $0.044 \pm 0.012$ & $0.034 \pm 0.014$ & $0.040 \pm 0.008$ \\
\hline MRT (min) & $27.1 \pm 2.8$ & $29.4 \pm 9.5$ & $26.0 \pm 3.0$ \\
\hline AUC $\left(\mathrm{min}^{*} \mu \mathrm{g} / \mathrm{ml}\right)$ & $86 \pm 23$ & $200 \pm 96$ & $367 \pm 53$ \\
\hline
\end{tabular}


Table 3: Plasma pharmacokinetic parameters of methotrexate after intrathecal ventricular and intrathecal lumbar administration in rabbit.

\begin{tabular}{ccc}
\hline Parameters & Ventricular administration & Lumbar administration \\
\hline AUC $\left(\mathbf{m i n}^{*} \boldsymbol{\mu g} / \mathrm{ml}\right)$ & $207 \pm 72$ & $219 \pm 92$ \\
$\mathrm{~T} 1 / 2(\mathrm{~min})$ & $192 \pm 103$ & $162 \pm 96$ \\
Tmax $(\mathrm{min})$ & $85 \pm 69$ & $43 \pm 38$ \\
Cmax $(\boldsymbol{\mu g} / \mathrm{ml})$ & $0.93 \pm 0.67$ & $0.94 \pm 0.33$ \\
\hline
\end{tabular}


